\title{
THE CHARACTERIZATION OF THE STRESS FIELDS NEAR A CRACK TIP FOR A COMPACT SPECIMEN FOR ELASTIC-PLASTIC MATERIALS DOMINATED BY THE PLANE STRAIN STATE
}

\author{
M. GRABA \\ Kielce University and Technology \\ Faculty of Mechatronics and Mechanical Engineering \\ Department of Manufacturing Engineering and Metrology \\ Al. 1000-lecia PP 7, 25-314 Kielce, POLAND \\ E-mail:mgraba@tu.kielce.pl
}

\begin{abstract}
The paper presents a comprehensive analysis of the stress field near a crack tip for a compact specimen dominated by the plane strain state using the finite element method. The analysis also includes the calculation of some parameters of in-plane constraints, both for small and large strain assumptions. It discusses the influence of the material characteristic, relative crack length and external load for the stress field, and the in-plane constraint parameter. The approximation formulas for some in-plane constraint parameters are presented.
\end{abstract}

Key words: fracture mechanics, $\mathrm{C}(\mathrm{T})$, stress field, FEM, constraints, plane strain, plastic zone, crack.

\section{Introduction}

One of many basic specimens used in fracture mechanics is a compact specimen, denoted by $\mathrm{C}(\mathrm{T})$. It appears in the ASTM standards [1, 2], British Standards [3, 4] or even the norm that is still in force in Poland in the didactic or research process [5]. The $\mathrm{C}(\mathrm{T})$ specimen was repeatedly used by various researchers to assess the cracking phenomena and fracture toughness of various materials [6-8]. The development of research methods, as well as the need for calibration used in experimental designs, have also repeatedly been the subject of scientific papers [9-11], in which the authors discussed the method of determining critical fracture toughness values based on $\mathrm{C}(\mathrm{T})$ specimens.

In 2012, Zhu and Joyce [12] presented an overview of methods for determining fracture toughness using $\mathrm{C}(\mathrm{T}), \mathrm{SEN}(\mathrm{B})$ and $\mathrm{CC}(\mathrm{T})$ specimens, indicating the need to consider the influence of geometric constraints in formulas approximating the equations of the $J-R$ curves. The parameters of geometrical constraints mentioned in the paper [12] include the $Q$-stress ( $Q$-parameter) defined by O'Dowd and Shih [1314] and the $A_{2}$ parameter (described also as $A_{2}$ amplitude) discussed by Yang et al. [15]. It should be remembered, however, that both parameters $-Q$ and $A_{2}$ are determined by numerical calculations with the assumption of small deformations and displacements, which leads to obtaining singular stress distributions near the crack tip (Fig.1a). It can be said that both parameters are a correction of the HRR solution presented in $1968[16,17]$ and improve the description of stress fields near the crack tip taking into account the influence of the other parts of the asymptotic solution.

As it is known, in the real structural element, the stresses in front of the crack tip are finite - such a distribution in numerical calculations is obtained by assuming large strains and large displacements (Fig.1a), which in the case of stress distribution leads to reach a maximum of the crack opening stress at a specific distance from the crack tip [18, 19] (Fig.1a). The value of this maximum, as well as its position near the crack tip, was used in [18] in the proposal of a modified crack criterion based on the RKR hypothesis [19]. The mentioned fracture criterion also uses the Q-stresses defined by O'Dowd and Shih $[13,14]$. It should be noted that the level of maximum stresses and their position near the crack tip depends on the material 
characteristics, geometry, and external load (Fig.1b), which is also shown in [18]. The same applies to the $Q$ parameter, commonly referred to as $Q$-stresses; it also depends on the geometry of the structural element, material or external load (Fig.1c).

a)

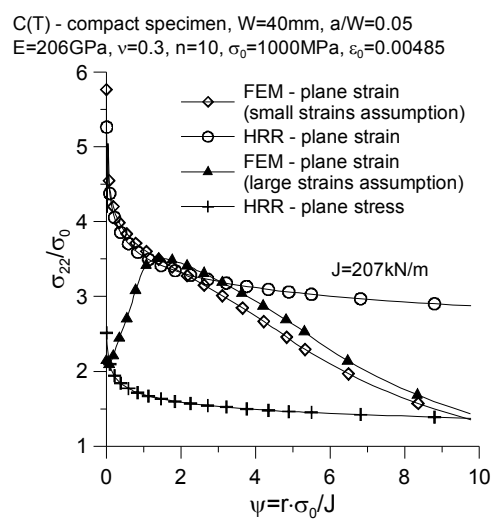

b)

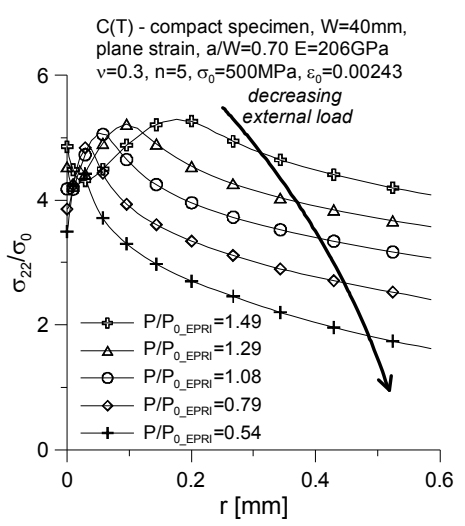

c)

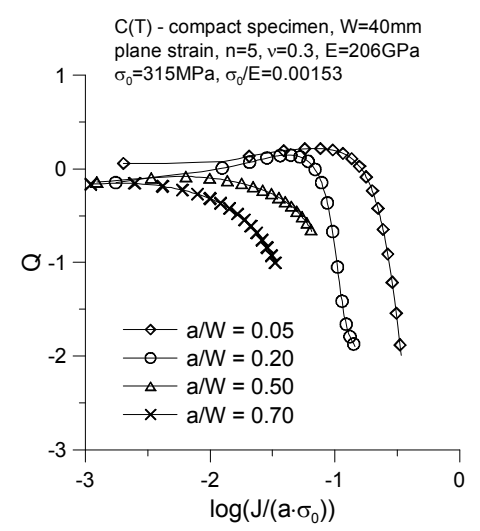

Fig.1. a) The stress distribution near the crack tip for $\mathrm{C}(\mathrm{T})$; b) The influence of the external load on the maximum crack opening stress (normalized by yield stress) for $\mathrm{C}(\mathrm{T})$ specimens; $\mathrm{c}$ ) The influence of the crack length on the $Q=f\left(\log \left(J /\left(a \cdot \sigma_{0}\right)\right)\right.$ trajectories for $\mathrm{C}(\mathrm{T})$ specimens (all graphs made on own calculations, using a method and presentation given by [21-24]).

The applications of the fracture mechanics to solving practical engineering problems require knowledge of the $Q$-parameter or/and the Maximum Crack Opening Stresses (MCOS) and their position in front of the crack tip. In addition, these parameters, generally referred to as in-plane constraints, are determined by carrying out comprehensive numerical calculations, the results of which are subject to detailed analysis (post-processing). The development of a numerical model allowing to estimate the measures of inplane constraints is not a trivial problem, as shown in [20]. Based on previous achievements [21-24], the author of this article presents a catalog of numerical solutions and their approximations, which for compact specimens allow to estimate the values of selected measurements of in-plane constraints depending on external load, crack length or material characteristics.

The concept of in-plane geometric constraints $[18,25,26]$ should be understood as the resistance that the material of a structural element puts on developing plastic deformations. In fracture mechanics, in-plane geometric constraints are generally determined for plane strain using O'Dowd's $Q$-stress [13, 14], which are the difference between the actual stresses in the structural element (determined by the Finite Element Method - FEM) and HRR solution (shown in [21-23] for different geometries of the basic fracture specimens SEN(B), CC(T), SEN(T)), determined according to theoretical formulas [16, 17]. In the case of plane strain, the $Q$-stresses usually have a non-zero value [21-23]. Therefore, speaking of a low level of in-plane constraints characteristic for specimens with short and very short cracks, we mean a considerably negative value of $Q$ stresses, but when speaking of a high level of in-plane constraints - characteristic for specimens containing long and very long cracks, we mean high $Q$-stress value $[13,14]$. Therefore, for a comprehensive analysis of the stress state near the front of the crack in elastic-plastic materials dominated by plane strain, the choice of four different variants of the relative crack length is not coincidental. The same remarks apply to the FEM analysis carried out with the assumption of large deformations [24]. Both the maximum stresses opening up the fracture surfaces and their position near the crack tip depend on the relative length of the crack [24].

The considerations presented in [20] (some results were presented in [18]) showed, that the distribution of stresses near the crack tip in the case of assumptions of large strains is sensitive to the parameters of the FEM model (fracture tip modeling, crack radius size, finite element type, finite element 
size [20]) - FEM model with the assumption of small deformations does not show such a sensitivity [20]. It turns out that the determination of convergent stress distributions, and thus the right values of geometrical constraint parameters (for which the $Q$-stress, $A_{2}$ amplitude, maximum crack opening stress and their position from the crack tip can be considered), requires proper pre- and post-processing. The result of the analyses should be a catalog of numerical solutions which, for the desired material and geometric characteristics, will allow to quickly assess the level of selected in-plane geometric constraints, depending on the external load, which can be expressed in the case of elastic-plastic materials using the $J$-integral or the external load normalized by limit load [21-24].

A properly developed catalog of numerical solutions containing the values of geometric in-plane constraints can be used for:

- a modified description of $J-R$ curves [12];

- assessment of fracture toughness using the selected cracking criterion $[18,19,25,26]$;

- or for assessing the strength of a defect - a structural element containing a defect, using the appropriate level of the Failure Assessment Diagram (FAD) analysis given in FITNET procedures [25, 26].

For this reason, in this paper an attempt was made to characterize the stress field near the crack tip in the C(T) specimen (otherwise called "compact specimen"), made of elastic-plastic material dominated by a plane strain. In the first step of the analysis, based on the theory of O'Dowd and Shih [13, 14], for sixteen hypothetical materials (differing by yield stress $\sigma_{0}$ and strain hardening exponent $n$ ), the level of the $Q$ parameter was determined, as a function of $J$-integral (or its normalized value), using a well-known relationship [13-14, 21-23]

$$
Q=\frac{\left(\sigma_{\theta \theta}\right)_{F E M}-\left(\sigma_{\theta \theta}\right)_{H R R}}{\sigma_{0}} \quad \text { for } \quad \theta=0 \quad \text { and } \quad \frac{r \sigma_{0}}{J}=2
$$

where $\left(\sigma_{\theta \theta}\right)_{F E M}$ is the stress value calculated using FEM and $\left(\sigma_{\theta \theta}\right)_{H R R}$ is stress value evaluated form HRR solution [16, 17] - both terms should be computed at a distance equal to $r=2 J / \sigma_{0}$ for the direction characterized by angle $\theta=0$. The $\left(\sigma_{\theta \theta}\right)_{H R R}$ were calculated using the following HRR solution $[16,17]$

$$
\sigma_{i j}=\sigma_{0}\left(\frac{J}{\alpha \sigma_{0} \varepsilon_{0} I_{n} r}\right)^{\frac{1}{1+n}} \tilde{\sigma}_{i j}(\theta, n)
$$

where $r$ and $\theta$ are polar coordinates of the coordinate system located at the crack tip, $\sigma_{i j}$ are the components of the stress tensor, $J$ is the $J$-integral, $n$ is R-O exponent (strain hardening exponent), $\alpha$ is R-O constant (strain hardening constant), $\sigma_{0}$ is yield stress, $\varepsilon_{0}$ is strain related to $\sigma_{0}$ through relationship $\varepsilon_{0}=\sigma_{0} / \mathrm{E}, \mathrm{E}$ is the Young modulus. Functions $\tilde{\sigma}_{i j}(n, \theta), I_{n}(n)$ must be found by solving the fourth order non-linear homogenous differential equation independently for plane stress and plane strain, using the computer program presented in [27].

In this place, however, one should write a few remarks about Q-stresses and other parameters of geometrical constraints, which can be used in practical problems of fracture mechanics. The in plane constraint parameter denoted as Q, is based on the plane strain crack tip stress fields and it has been adopted to incorporate the constraint effect in fracture assessment of cracked structures in the R6 [42] and BS7910 procedures [43]. But the Q parameter has limitation and loses its validity under large scale yielding and bending dominant loading, what was presented in [44]. In addition, both in-plane and out-of-plane constraints are generally existed in the actual engineering structures $[45,46]$. Therefore, a unified constraint parameter which can characterize both constraints is required for a more accurate fracture assessment. In recent years, some unified constraint parameters have been proposed and developed [47-51].

In the second step of the analysis, making the assumption of large deformations and large displacements, conducting specific numerical calculations, a second part of the catalog of numerical solutions was developed containing the maximum stresses opening the crack surfaces and their position near 
the crack tip. All numerical results were given graphically, as the changes of parameters $\xi_{o}=\sigma_{22} \max _{0} / \sigma_{0}$ and $\psi_{o}=\left(x_{22} \max \cdot \sigma_{0}\right) / J$, which denote the maximum stress opening the crack surfaces normalized by the yield strengths and the normalized position $\psi_{o}$ near the crack tip (the physical location of the maximum stress opening the crack surfaces is denoted by $x_{22} \max$ ) respectively.

In the last step, next to the conclusions drawn, simple approximation formulas were proposed that allow to estimate the selected values of in-plane geometrical constraint parameters for a given material and geometric combination. All the results of numerical calculations and their approximations can be used in solving the various engineering problems mentioned above.

\section{Geometry specimen, loading, material characteristic, FEM details}

In the calculations, the $\mathrm{C}(\mathrm{T})$ specimen was modeled in accordance with the applicable standards, based on EPRI [28], BS [3, 4] and ASTM [1, 2] (Fig.2a). The width of the specimen was set to $W=40 \mathrm{~mm}$, four different relative crack lengths were modeled $(a / W=\{0.05,0.20,0.50,0.70\}$, where $a$ means crack length), which guarantees a diversified level of in-plane constraints around the crack tip. In the calculations, sixteen hypothetical real stress-strain curves described by the power law (2.1) were used

$$
\frac{\varepsilon}{\varepsilon_{0}}=\left\{\begin{array}{ccc}
\sigma / \sigma_{0} & \text { for } & \sigma \leq \sigma_{0} \\
\alpha \cdot\left(\sigma / \sigma_{0}\right)^{n} & \text { for } & \sigma>\sigma_{0}
\end{array}\right.
$$

wherein, that the power constant $\alpha=1$, Young modulus E $=206 \mathrm{GPa}$, Poisson's ratio $v=0.3$, yield stress $\sigma_{0}=\{315,500,1000,1500\} \mathrm{MPa}$, the strain hardening exponent $n=\{3.36,5,10,20\}$. The calculations were carried out in a fairly wide range of mechanical properties - from materials that strongly strengthened to weakly reinforcing materials. The exemplary stress-strain curves used in the numerical calculation are presented in Fig.2b.

a)

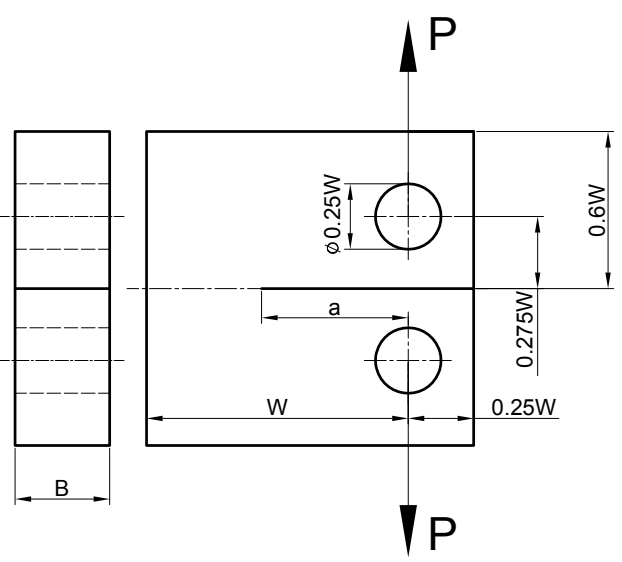

b)

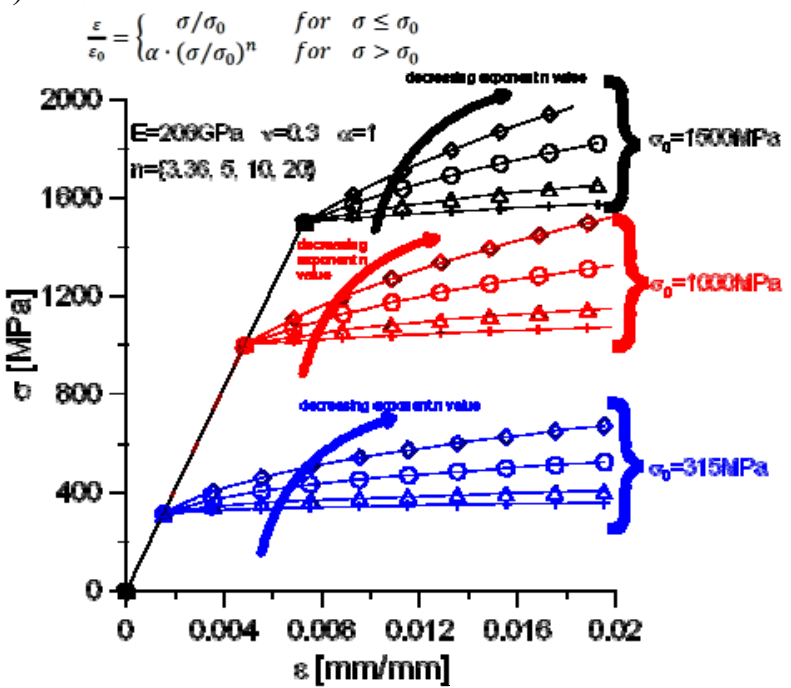

Fig.2. a) The C(T) specimen; b) The exemplary stress-strain curves used in the numerical calculation (twelve of the sixteen model stress -strain curves).

Using the existing symmetry axes, it was decided to model only half of the $\mathrm{C}(\mathrm{T})$ specimen in the FEM analysis (Fig.1a) [29, 30]. In the numerical calculations the contact issue was solved - the load of C(T) specimens was carried out with the help of a spindle (i.e., pin) (Fig.3a), characterized by diameter $\phi 10 \mathrm{~mm}$, which was modeled in the form of half of the arch, divided into 180 two-node contact Finite Elements (FEs). 
An external load was applied to the pin in the form of a linearly increasing displacement. There were 181 nodes on these contact surfaces realizing the external load of the specimen.

The crack tip was modeled in the form of a quarter of the arch, with radius $r_{w}$ within the limits of $(1 \div 5) \mu \mathrm{m}$. This means that the radius of the crack tip was in extreme cases 40000 and 8000 times smaller than the width of the sample $(W=40 \mathrm{~mm})$. This crack tip was divided into 20 parts together with the density of the elements towards the edge lying in the axis of the specimen (depending on the material model and relative crack length, the edge finite elements were $(5 \div 20)$ times smaller than the largest elements located in the central part of the arch) - see Fig.3c. The size of the radius of the crack tip was determined similarly as in the case of other bending specimens [20,23,24], including the level of external loading, material characteristic (expressed by the ratio $\sigma_{0} / \mathrm{E}$ and exponent $n$ ) and relative crack length (expressed by $a / W$ ). For each specimen, the peak area with a radius equal to approximately $(1.0 \div 2.5) \mathrm{mm}$ was divided into $(35 \div 50)$ finite elements (FEs), wherein the smallest FE located at the crack tip was 100 times smaller than the previous one (Fig.3b). This meant that, in extreme cases, the smallest FE, located just next to the crack tip, represented about $1 / 70700$ or $1 / 101000$ of the width $W$ of the specimen, and the largest modeling the peak area has the size of about $1 / 707$ or $1 / 1010$ of the specimen width.

a)
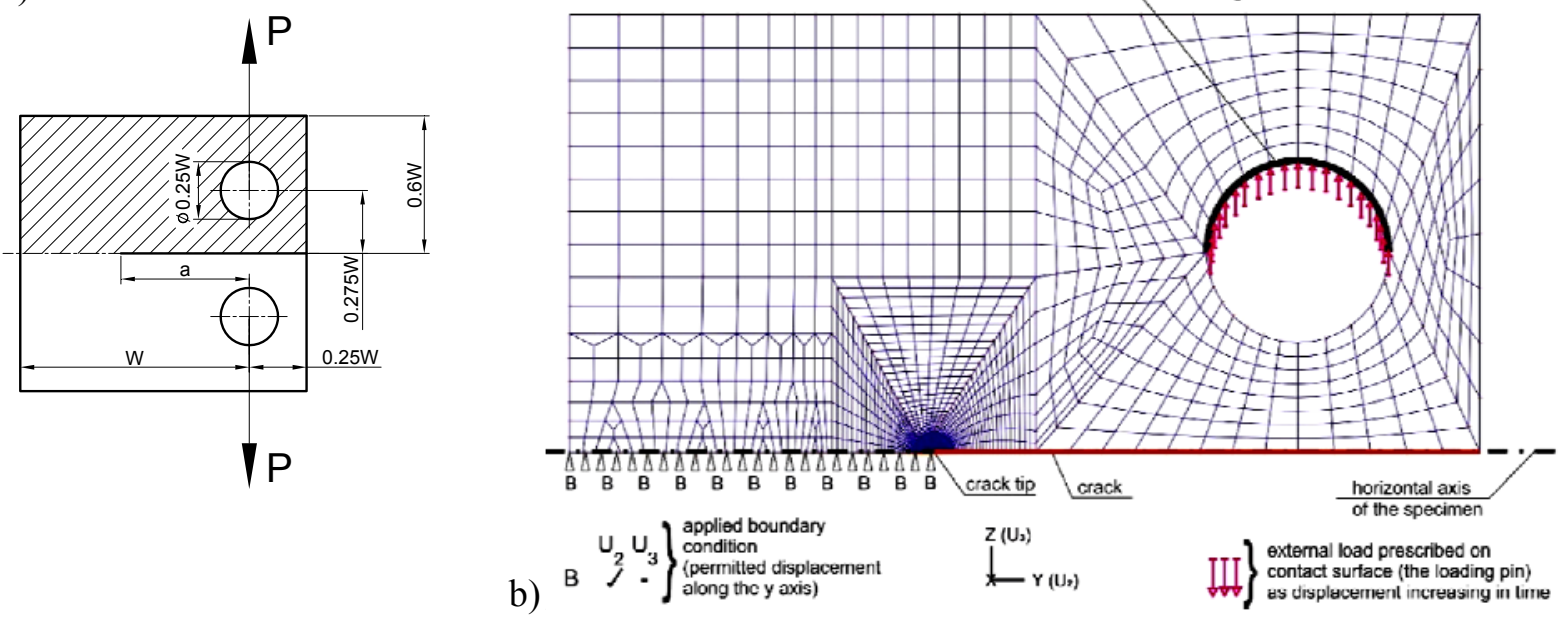

c)

d)
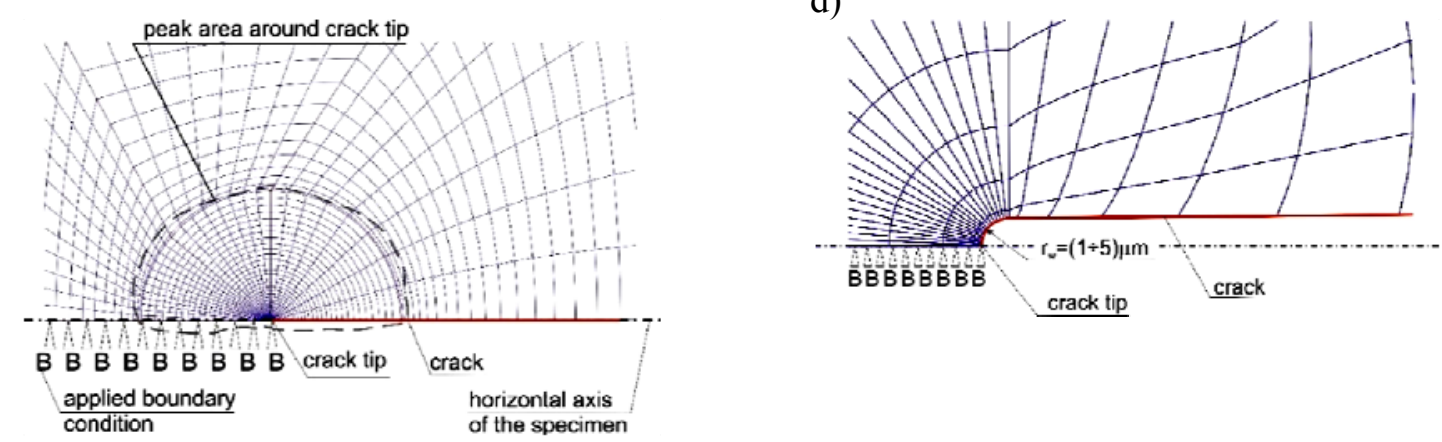

Fig.3. The $\mathrm{C}(\mathrm{T})$ specimen used in the numerical program: a) schematic technical drawing of the $\mathrm{C}(\mathrm{T})$ specimen with hatched part which was used in the FEM analysis; b) a half of the C(T) specimen with applied boundary conditions and external load; c) zoom of the peak area near crack tip; d) the shape of the crack tip.

The FEM analysis was carried out in parallel with the assumption of small deformations and small displacements (necessary to determine the Q-stresses defined by O'Dowd $[13,14]$ - see Eq.(1.1)) and assuming large strains and large displacements (necessary to determine maximum stresses opening the fracture surfaces). The FEM model was filled with nine-node Finite Elements (FEs), using the "2-D 
SOLID plane strain" type and "mixed" interpolation with nine Numerical Integration Points (NIP) $[29,30]$.

The $J$-integral referred to as the crack driving force, or the amplitude of the singular stress field near the crack tip, was determined using the method of virtual crack length growth [29, 30]. For the purposes of this paper, several integrating contours were defined, and taking into account the principle proposed by Guo [32] for three-dimensional solutions, where the integration contour required for the numerical estimation of the $J$-integral should be defined as "far-field contour" [32]. This approach also guarantees the invariance of the $J$-integral when assuming the analysis of large deformations and displacements, as shown in [20]. The $J$ integral values obtained using virtual crack length growth were the same as the results for calculations done using the $J$-integral definition given by Rice [38], which was presented in [39].

An additional element of the numerical analysis was also the verification of solutions in the range of limit loads for the $\mathrm{C}(\mathrm{T})$ specimen, which in the case of plane strain state domination was given in [28]

$$
P_{0}=1.455 \cdot \eta \cdot b \cdot \sigma_{0} \cdot B
$$

wherein, $b$ is uncracked ligament $(b=W-a), B$ is specimen thickness (for plane strain it is assumed $B=1 m$ ) and $\eta$ is the function of the specimen geometry $\left(\eta=\left[(2 a / b)^{2}+2(2 a / b)+2\right]^{\frac{1}{2}}+[2 a / b+1]\right)$.

a)

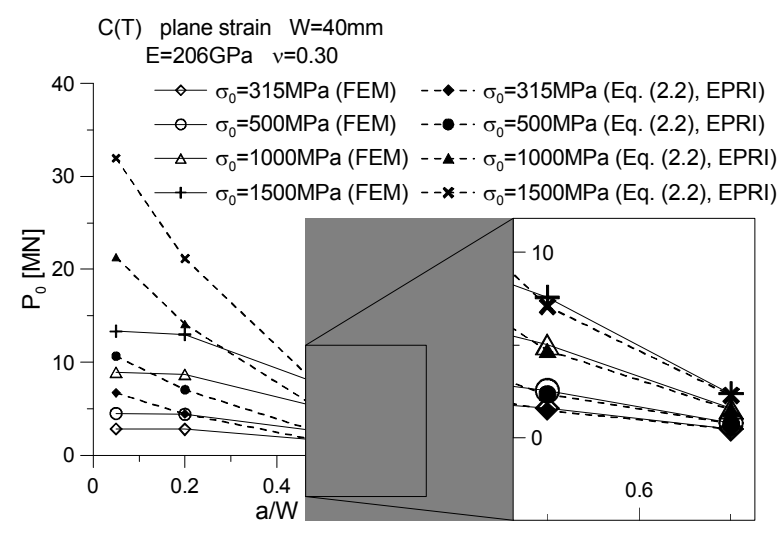

b)

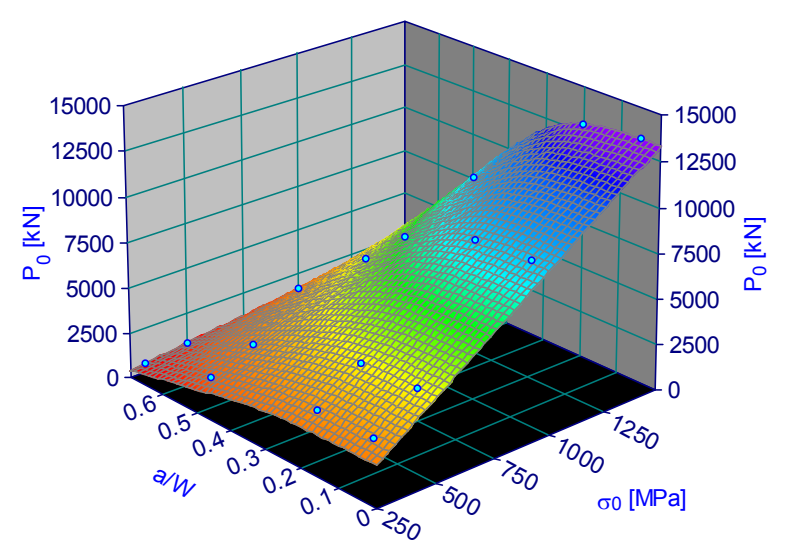

Fig.4. a) Comparison of the calculated numerical limit load value and EPRI solutions [28] for C(T) specimen dominated by the plane strain state; b) Influence of the yield stress $\sigma_{0}$ and relative crack length $a / W$ on limit loads for $\mathrm{C}(\mathrm{T})$ specimen dominated by the plane strain state (the approximation plane described by Eq.(2.3)).

The estimation of the limit loads was carried out on the same finite element grid as main calculations, assuming only elastic - a perfectly plastic material model. This step was carried out due to discrepancies between numerical solutions and analytical solutions for other basic geometries of fracture mechanics, which were mentioned in [33-35, 41]. The analysis confirmed the satisfactory convergence of the formula (2.2) with the numerical solution for the case of the crack, characterized by relative length $a / W=0.50$ and $a / W=0.70$ (formula (2.2) guarantees for the above-mentioned crack length values lower than the numerically estimated about $8 \%$ and $5 \%$ respectively (Fig.4)) In the case of very short and short cracks $(a / W=0.05$ and $a / W=0.20$ respectively), the values obtained with the formula (2.2) are inflated in relation to those numerically estimated by almost $58 \%$ and $38 \%$, respectively. 
The estimated values of limit loads presented above were subjected to simple approximation using available mathematical tools. One of the many proposed formulas that can be used to estimate the limit load value $P_{0}$ is the polynomial form of dependence, taking into account the plasticity limit $\sigma_{0}$ inserted in [MPa] and the relative crack length $a / W$

$$
P_{0}=A_{1}+A_{2} \cdot \sigma_{0}+A_{3} \cdot\left(\frac{a}{W}\right)+A_{4} \cdot\left(\sigma_{0}\right)^{2}+A_{5} \cdot\left(\frac{a}{W}\right)^{2}+A_{6} \cdot \sigma_{0} \cdot\left(\frac{a}{W}\right)
$$

where the limit load value $P_{0}$ is obtained in [kN], with the matching factor $R^{2}=0.993$, using the following values of approximation factors: $A_{1}=-933.154, A_{2}=10.262, A_{3}=9612.613, A_{4}=-5.91 \cdot 10^{-5}, A_{5}=-12986.874$, $A_{6}=-11.429$.

The next paragraph presents the results of numerical calculations that characterize the stress field near the crack tip in $C(T)$ specimens (compact specimens). The reference to the relative values of the force acting on the specimen given in the chapters will refer to the cases of normalization by the value of the limit load determined for the purpose of this paper.

\section{Some numerical results}

All calculations were done using the ADINA program [29, 30], using the analysis schemes developed over the years [18, 24-27]. The post-processing analysis was done for numerical results obtained for the assumption of small and large strains. In addition to the level of the selected geometric constraints, the level of selected stress tensor components, effective stresses calculated according to the Huber-MissesHencky hypothesis, the size of the plastic zone, the triaxiality of stresses, and the level of accumulated plastic strain were also considered. Some numerical results are presented below for points lying in the direction $\theta=0$ - along the line from the crack tip.

\subsection{Small strain assumption}

Figure 5 presents the distribution of crack surfaces opening stresses near the crack of the fracture for three $\mathrm{C}(\mathrm{T})$ specimens, differing in the relative crack length $a / W$, for six levels of external load, normalized by the limit load $P_{0}$, estimated for the purpose of this paper.

Figures 5a-c show the variations in the stresses opening the crack surfaces as a function of the normalized position relative to the crack tip, and Figs 5d-f as a function of the physical distance from the crack tip. As we move away from the crack tip, we observe a decrease in the level of stresses that open the fracture surfaces, which in the crack tip are aimed at a singular state. Referring to the changes presented in Figs $5 \mathrm{~d}-\mathrm{f}$, it should be stated that the higher the level of external load, the greater the value of stresses opening the fracture surfaces in the same physical location near the crack tip.

The same tendency as described above is observed in the changes of effective stresses, presented as a function of the normalized distance from the crack tip (Figs 6a-c) and as a function of the physical distance (Figs 6d-f). The higher the level of external load, the greater the level of effective stress in the same physical location near the crack tip (Figs 6d-f). However, by normalizing the distance from the crack tip, a situation is reached, where the level of effective stresses estimated at a specified normalized distance from the crack tip decreases with the increase of the external load. Effective stresses increase as we move closer to the crack tip, striving for infinity (a singular field). The level of effective stress near the crack tip is reflected in developing plastic zones, which were estimated based on the level of effective stress - a plasticized region is taken to be a region where effective stresses are equal to or greater than the yield stress. 
a)

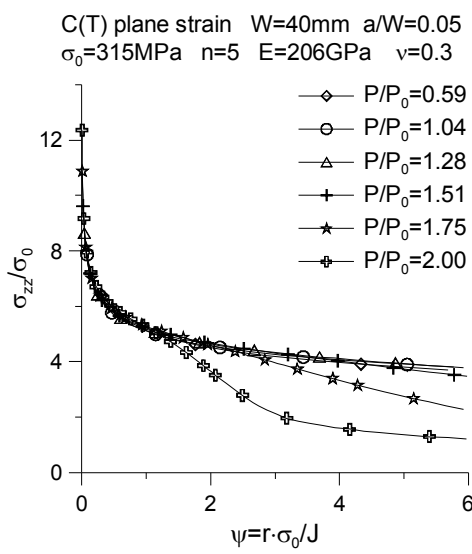

d)

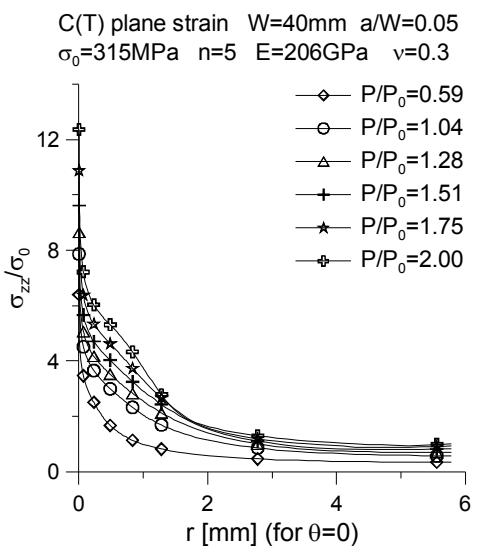

b)

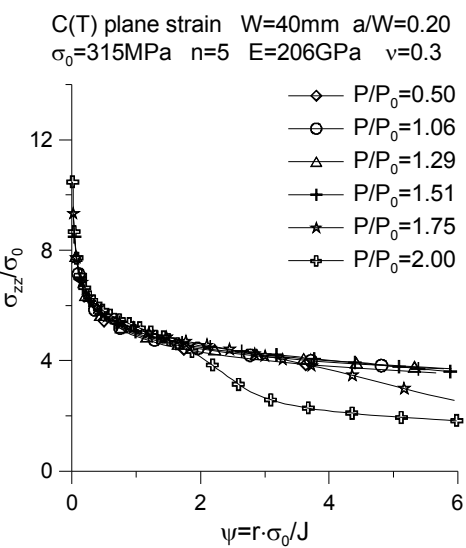

e)

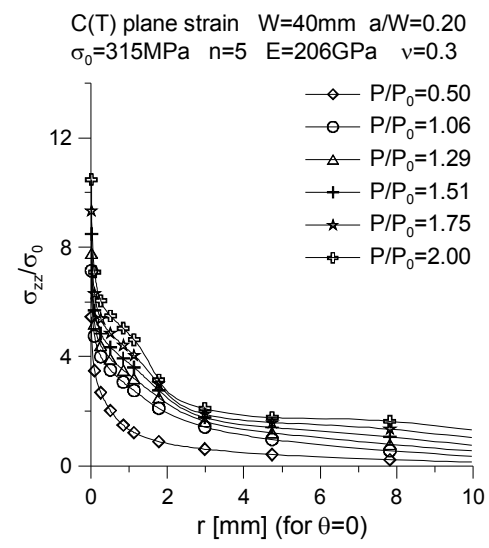

c)

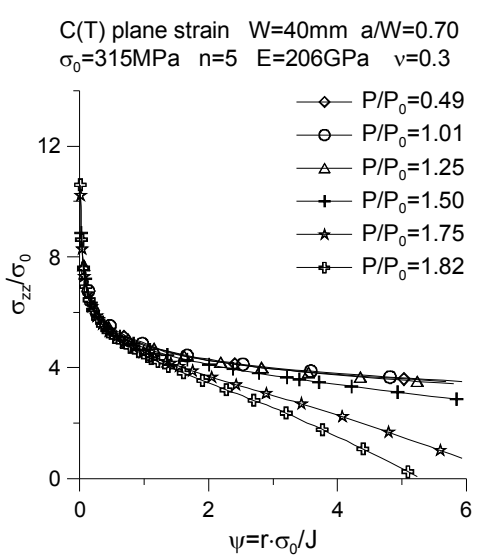

f)

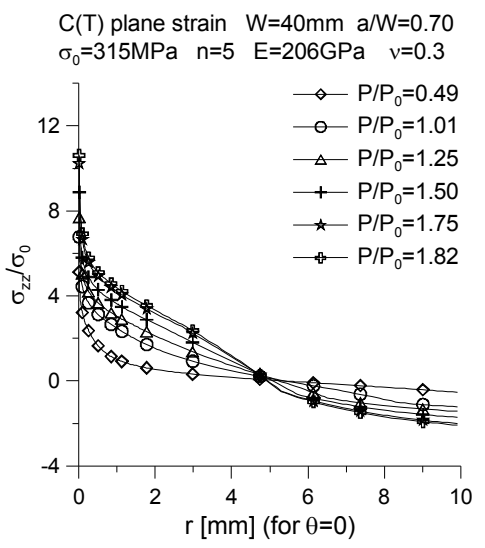

Fig.5. The influence of the level of external load on crack opening stress $\sigma_{z z}$ for $C(T)$ specimens dominated by plane strain (calculations for small strain assumptions): $\mathrm{a}, \mathrm{b}, \mathrm{c}-$ the stress distribution in the function normalized distance from crack tip $\left(\sigma_{z z} / \sigma_{0}=f\left(r \cdot \sigma_{0} / J\right)\right)$; d, e, f - the stress distribution in the function physical distance from crack tip $\left(\sigma_{z z} / \sigma_{0}=f(r)\right)$.

Normalization of the physical distance from the crack tip according to the scheme proposed by O'Dowd and Shih $[13,14]$ (the normalized distance is expressed by the product of physical distance $r$ and yield point $\sigma_{0}$ divided by the $J$-integral, as $\psi=r \cdot \sigma_{0} / J$ ) leads to a situation where the stresses opening the crack surfaces within the range of normalized distances $\psi=(0 \div 1.5)$ do not depend on the level of external load (Figs 5a-c). For a normalized distance from the crack tip $\psi \geq 1.5$, the effect of the external load $P / P_{0}$ on the crack opening stress is observed - the higher the level of external load, the smaller the stress values opening the fracture surfaces at the same normalized distance from the crack tip, expressed by the parameter $\psi=r \cdot \sigma_{0} / J$. 
a)

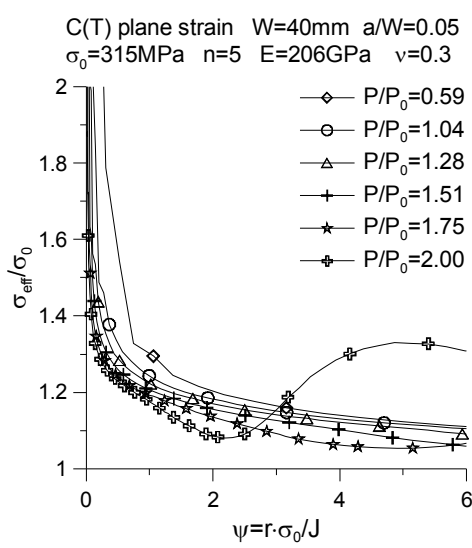

d)

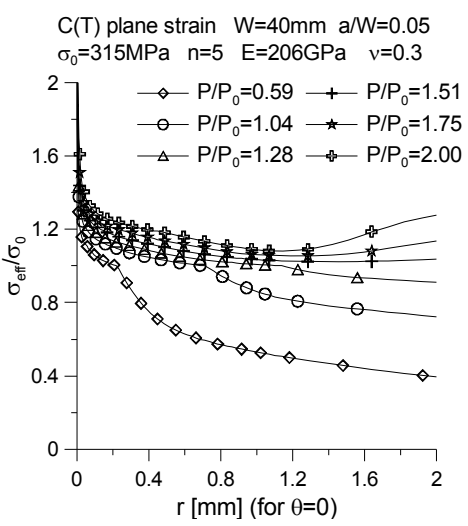

b)

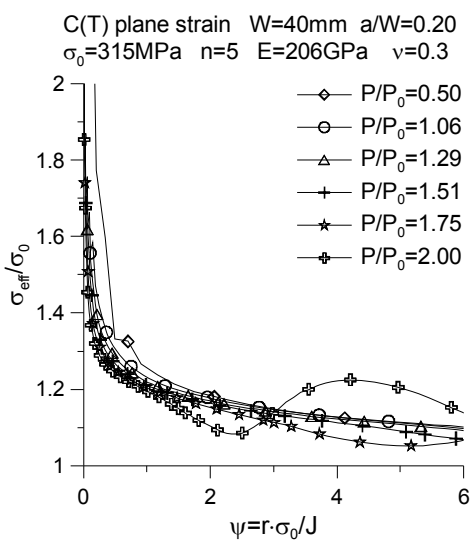

e)

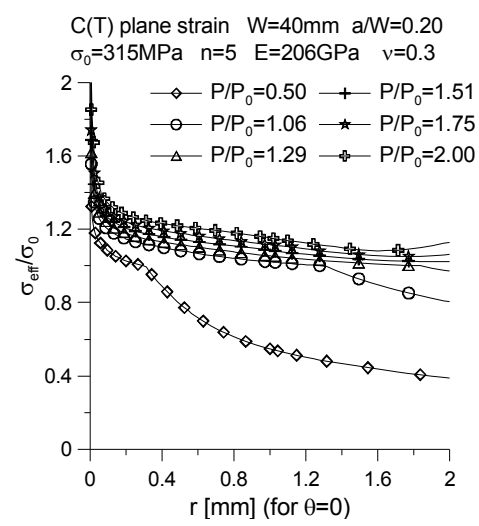

c)

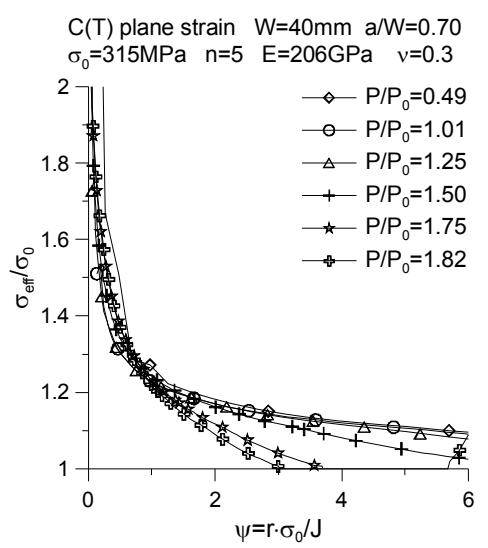

f)

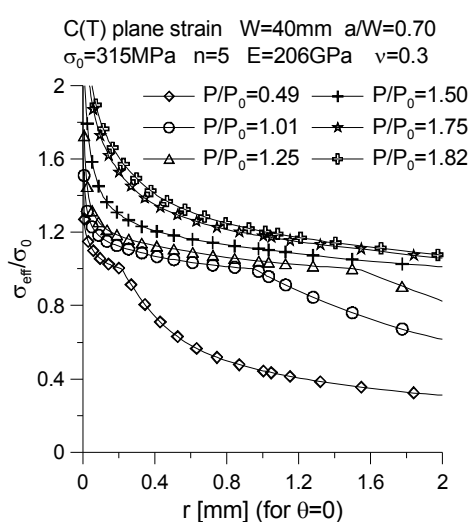

Fig.6. The influence of the level of external load on effective stress $\sigma_{\text {eff }}$ for $\mathrm{C}(\mathrm{T})$ specimens dominated by plane strain (calculations for small strain assumptions): a, b, c - the stress distribution in the function normalized distance from crack tip $\left(\sigma_{e f f} / \sigma_{0}=f\left(r \cdot \sigma_{0} / J\right)\right)$; d, e, f - the stress distribution in the function physical distance from crack tip $\left(\sigma_{e f f} / \sigma_{0}=f(r)\right)$.

Figure 7 shows the change in the shape and size of the plastic zone for three $\mathrm{C}(\mathrm{T})$ specimens differing in the relative crack length $a / W=\{0.05,0.20,0.70\}$, for three selected levels of external load $P / P_{0}=\{1.0,1.50,2.00\}$. As it can be seen, when the limit load level is reached $-P / P_{0}=1.00$, the plastic zone for any of the analyzed geometries does not cover the uncracked ligament of the specimen (Figs 7a, d, g). In the case of specimens containing very short and short cracks (respectively $a / W=0.05$ and $a / W=0.20$ ), the plastic zone develops in close proximity to the crack tip and regions located around the place of external load application (Figs 7a-c and Figs 7d-e). In the case of a specimen containing the crack characterized by $a / W=0.20$, the plastic zone increases from the free edge of the specimen (bottom and top) towards the expanding plastic zone located opposite the crack tip (Fig.7f).

In the case of $\mathrm{C}(\mathrm{T})$ specimens characterized by very long cracks $(a / W=0.70)$, the development of the plastic zone at the above-mentioned external load levels, shows trends presented in the professional literature [36] (Figs 7g-i). Among many analyzed geometries, full coverage of the uncracked ligament of the specimen, preventing the "transition" from the bottom to the upper edge of the specimen was observed in $\mathrm{C}(\mathrm{T})$ specimens with a relative crack length $a / W=0.20$ and external load $P / P_{0}=2.00$, and for specimens characterized by long and very long cracks (respectively $a / W=0.50$ and $a / W=0.70$ ), with external load $P / P_{0} \geq 1.50$. 
a)

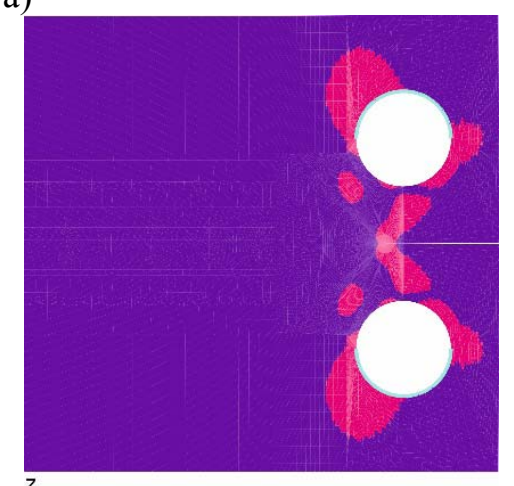

$z_{y}$ I- PLASTIC

d)

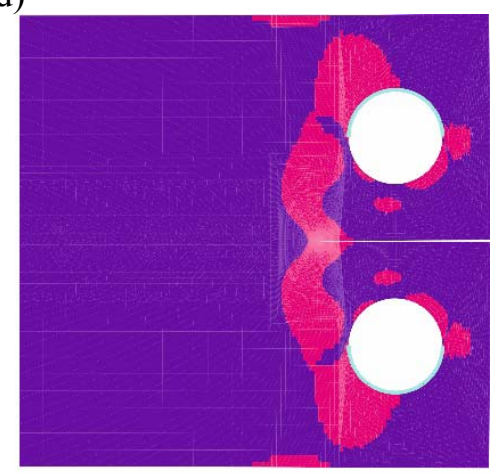

$\downarrow_{Y}^{Z}$ F PLASTIC

g)

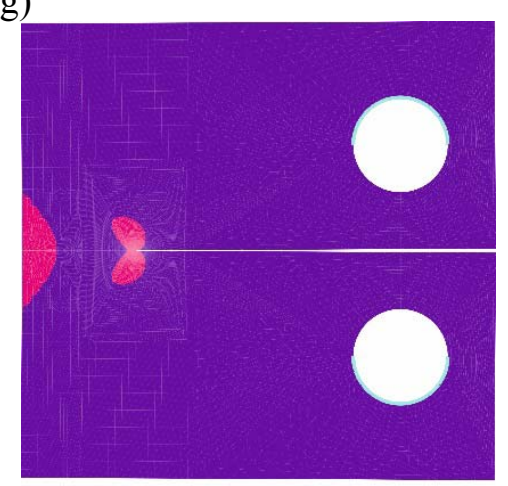
$\downarrow_{\text {Y }}^{Z}$ E- PLASTIC b)
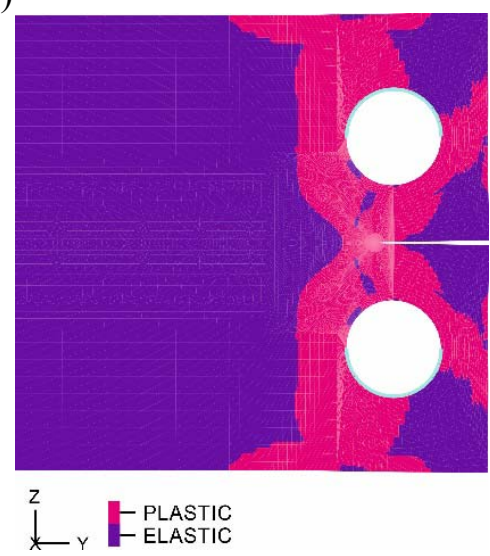

e)

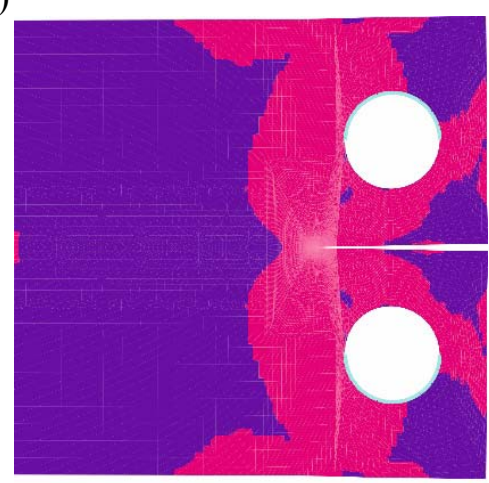

h)
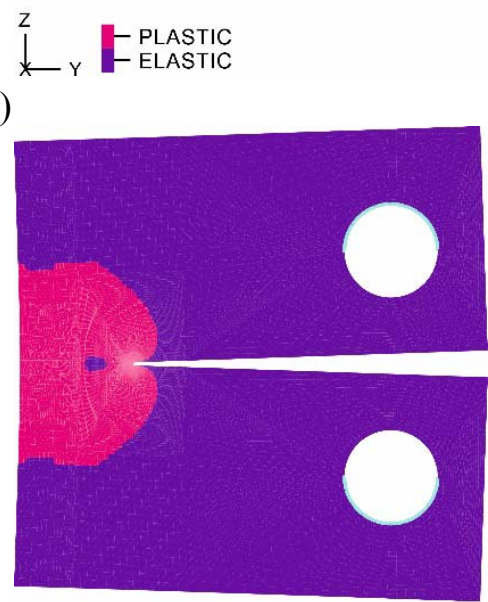

$\gtrless_{y}^{Z} \mathbf{F}_{\text {ELASTIC }}^{\text {PLASTIC }}$ c)

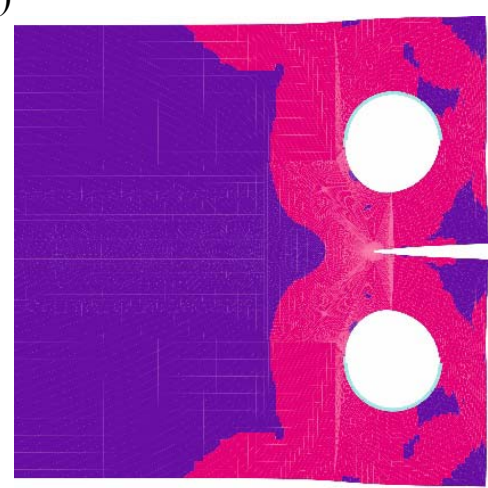

$\downarrow_{y}^{Z}$ F ELASTIC

f)

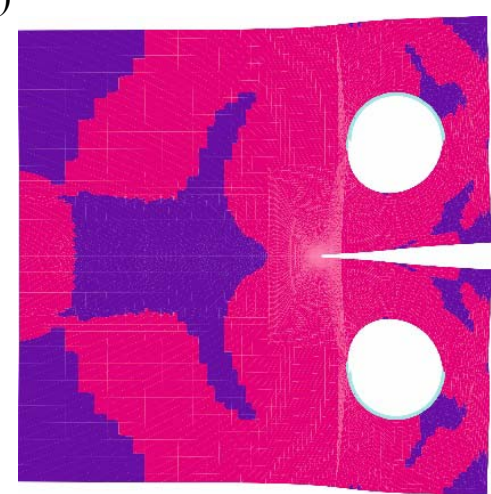

i)
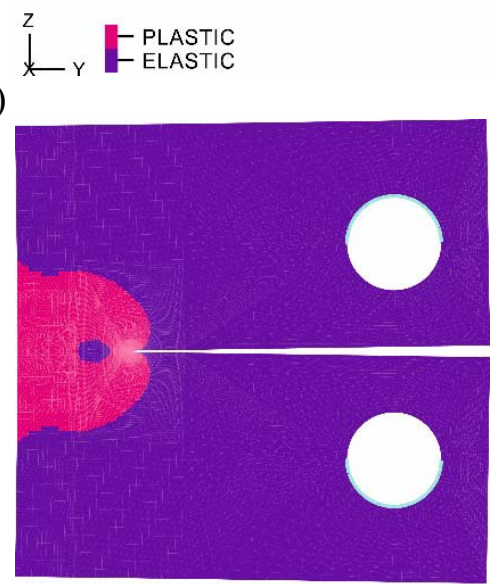

$\gtrless_{Y}^{Z}$ E ELASTIC

Fig.7. The influence of the level of external load on the shape and size of plastic zone for C(T) specimens dominated by plane strain (calculations for small strain assumptions) for material characterized by $n=5, \sigma_{0}=315 \mathrm{MPa}, \mathrm{E}=206 \mathrm{GPa}, \mathrm{v}=0.3: \mathrm{a}, \mathrm{b}, \mathrm{c}-$ the plastic zones for $\mathrm{C}(\mathrm{T})$ specimen characterized by $a / W=0.05$, for $P / P_{0}=\{1.00,1.50,2.00\}$ respectively; d, e, f - the plastic zones for $\mathrm{C}(\mathrm{T})$ specimen characterized by $a / W=0.20$, for $P / P_{0}=\{1.00,1.50,2.00\}$ respectively; g, h, I - the plastic zones for $\mathrm{C}(\mathrm{T})$ specimen characterized by $a / W=0.70$ for $P / P_{0}=\{1.00,1.50,2.00\}$ respectively.

The next parameter analyzed in the paper, related to the stress field near the crack tip, is the level of the stress triaxiality parameter, which in this paper is expressed by the ratio of stresses in the thickness 
direction denoted as $\sigma_{x x}$ and the sum of stresses $\sigma_{y y}$ and $\sigma_{z z}$ (Fig.8). This parameter in the case of the dominance of pure plane stress state reaches a value equal to zero, while in the case of the dominance of pure plane strain state, the value is equal to 0.5 [32]. The changes in the value of the stress triaxiality parameter presented in Fig.8 lead to the following conclusions. The higher the level of external load, the smaller the value of the stress triaxiality parameter, assuming that we measure it at a normalized distance, denoted by $\psi$, as mentioned above. However, if the values of the stress triaxiality coefficient measured at specific physical distances are evaluated, a phenomenon indicating an increase in the value of the stress triaxiality parameter with the increase of external load is observed, which is a natural phenomenon resulting from the increase of normal stresses due to the increase of external load. Also noteworthy is the completely different character of the curves, which are observed for $\mathrm{C}(\mathrm{T})$ specimens characterized by different crack length.

a)

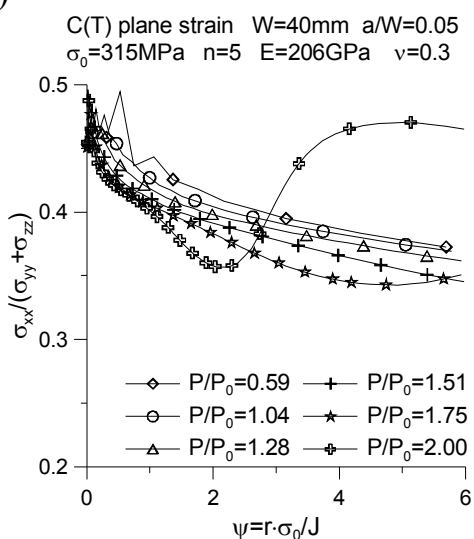

d)

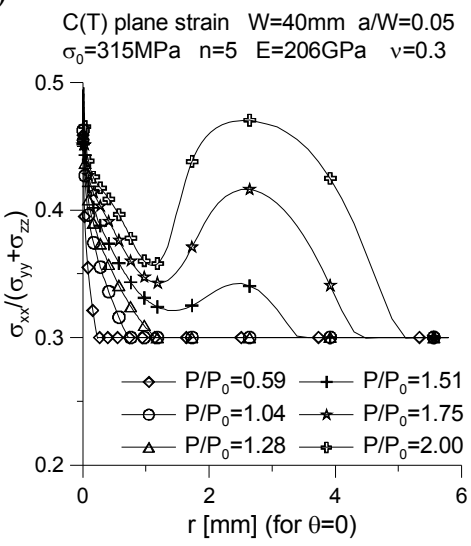

b)

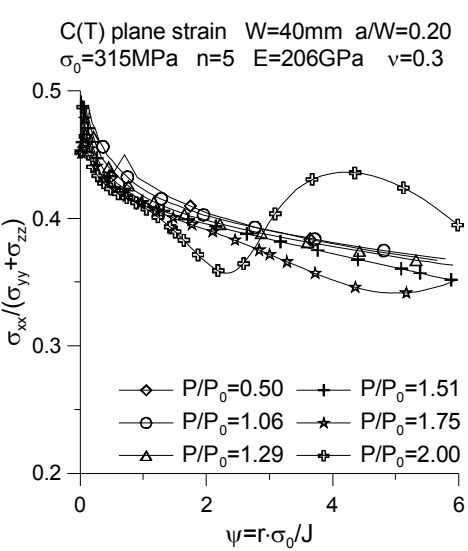

e)

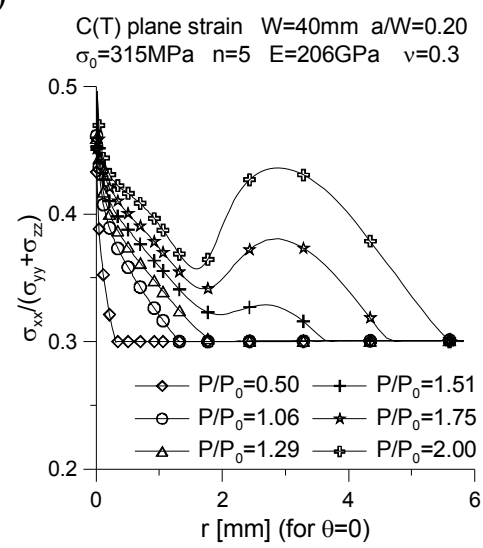

c)

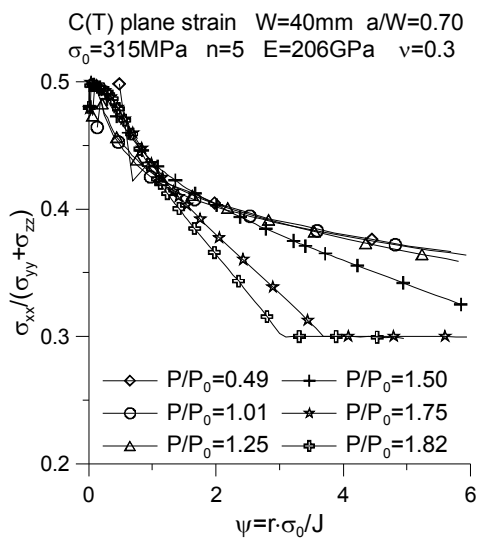

f)

$C(T)$ plane strain $W=40 \mathrm{~mm}$ a/W $=0.70$ $\sigma_{0}=315 \mathrm{MPa} \quad \mathrm{n}=5 \quad \mathrm{E}=206 \mathrm{GPa} \quad v=0.3$

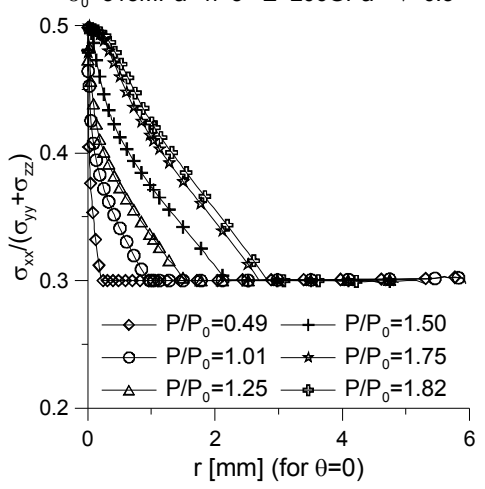

Fig.8. The influence of the level of external load on the triaxiality parameter $\sigma_{x x} /\left(\sigma_{y y}+\sigma_{z z}\right)$, for $\mathrm{C}(\mathrm{T})$ specimens dominated by plane strain (calculations for small strain assumptions): $\mathrm{a}, \mathrm{b}, \mathrm{c}-$ the stress distribution in the function normalized distance from crack tip $\left(\sigma_{x x}\left(\sigma_{y y}+\sigma_{z z}\right)=f\left(r \cdot \sigma_{0} / J\right)\right)$; d, e, $\mathrm{f}-$ the stress distribution in the function physical distance from crack tip $\left(\sigma_{x x} /\left(\sigma_{y y}+\sigma_{z z}\right)=f(r)\right)$.

The value of the stress triaxiality parameter decreases with increasing distance from the crack tip, striving for a set value equal to 0.3 , which is equal to the Poisson ratio assumed in calculations [32]. It should be noted that the analyzed stress triaxiality parameter, estimated according to the expression $\sigma_{x x} /\left(\sigma_{y y}+\sigma_{z z}\right)$, the value equal to 0.5 (characteristic for pure plane strain state) in the analyzed group of specimens reached almost at the crack tip, for specimens with a relative crack length $a / W=0.50$ and $a / W=0.70$ (Fig.8c and Fig.8f). In the case of $\mathrm{C}(\mathrm{T})$ specimens characterized by very short and short cracks $(a / W=0.05$ and $a / W=0.20$ respectively), the value of the stress triaxiality parameter at the tip of the crack was generally less than 0.5 . 
In addition to the stress field analysis, the influence of material characteristics and the relative crack length on selected measures of in-plane constraints were discussed (in this case it's about $Q$-stress defined by O'Dowd and Shih $[13,14]$ ), also taking into account the influence of external load expressed by $J$-integral (which may be accepted as a crack driving force). Figure 9 presents the changes in $Q$-stress values as a function of external load, relative to material characteristics and geometry of $\mathrm{C}(\mathrm{T})$ specimens. In the range of low external loads, it is noticed that $\mathrm{C}(\mathrm{T})$ specimens characterized by a high level of in-plane constraints (Fig.9). The increase in the relative crack length causes an increase in the value of $Q$-stresses - the in-plane constraints increase (Fig.9a). The increase in external load results in the decrease of the level of in-plane constraints expressed by $Q$-stress. The C(T) specimens characterized by a lower yield point reach a lower level of in-plane constraints faster (Fig.9b). The lower level of in-plane constraints is also characterized by $\mathrm{C}(\mathrm{T})$ specimens made of a strongly hardening material. The increase in the value of the strain hardening exponent (and thus the decrease in the material hardening level) causes an increase in the level of in-plane constraints expressed by $Q$-stresses (Fig.9c).

a)

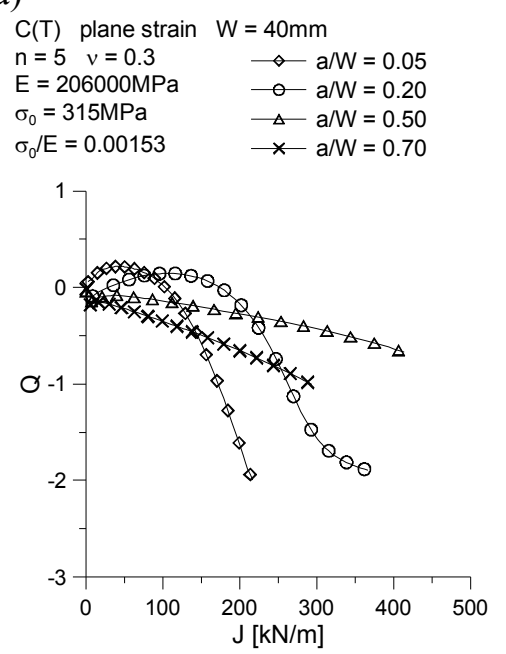

b)

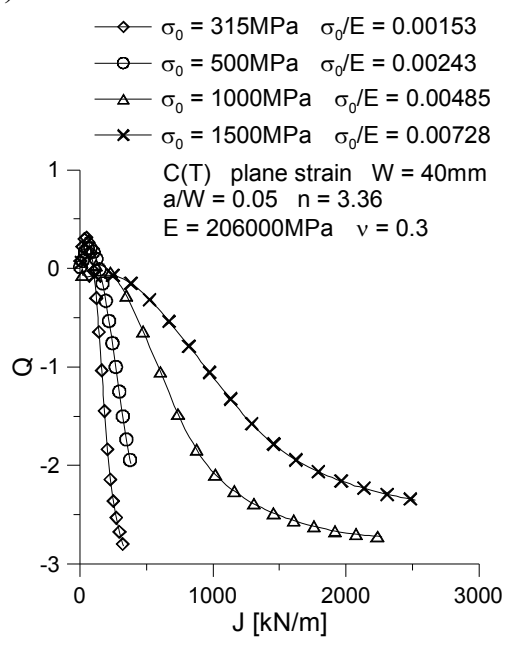

c)

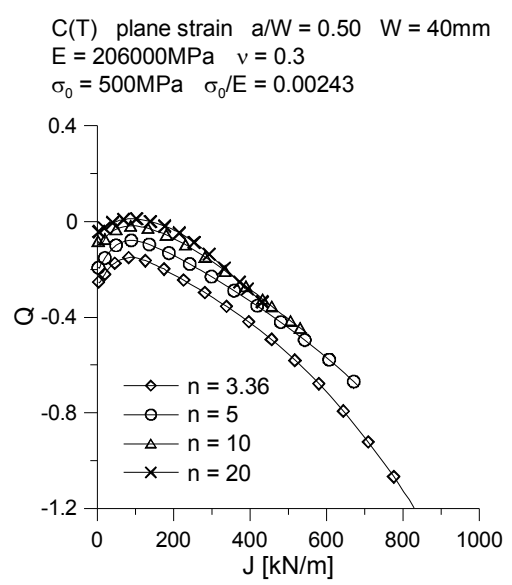

Fig.9. The influence of the relative crack length (a), yield stress (b) and strain hardening exponent (c) on the $J-Q$ trajectories for compact specimens.

The changes in the value of Q-stresses as a function of $J$-integral (which is considered to be the crack driving force and the control parameter of a singular stress and strain field near the crack tip in elastic-plastic materials) shown in Fig.9 can sometimes be quite troublesome, especially when mutual intersection of curves is observed for variously described geometry and material characteristics of specimens, especially in the range of small external loads $\left(P / P_{0}<1.00\right)$. This applies both to the curves $Q=f(J)$ for the determined material characteristics and various relative crack lengths $a / W$ (Fig.9a), as well as curves illustrating the influence of the yield point $\sigma_{0}$ (Fig.9b) or the influence of the strain hardening exponent $n$ (Fig.9c), with a predetermined relative crack length and other material characteristics. To avoid such problems, according to the recommendations of O'Dowd and Shih [13,14], graphs should be drawn showing the changes of $Q$-stress values as a function of decimal logit from the $J$-integral normalized by the product of crack length $a$ and yield point $\sigma_{0}-\log \left(J /\left(a \cdot \sigma_{0}\right)\right)$. This approach simplifies the qualitative analysis of numerical results, as well as quantitative, facilitating their approximation, especially with the use of third-degree polynomials, as shown in [21-23], obtaining a satisfactory convergence of numerical results and their approximation (Fig.10). 
a)

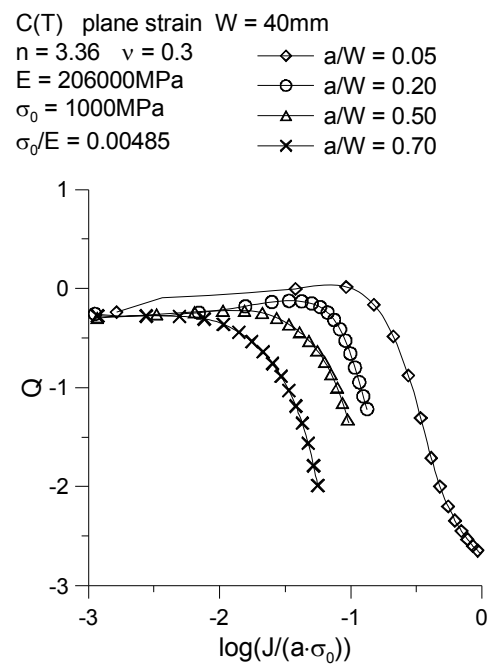

b)

c)
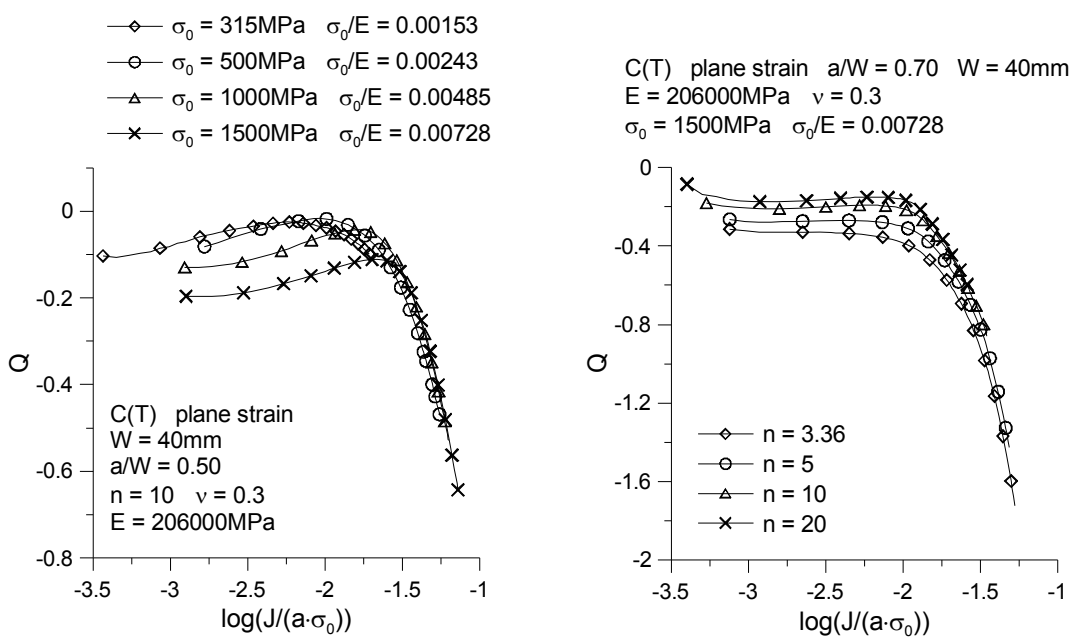

Fig.10. The influence of the relative crack length (a), yield stress (b) and strain hardening exponent (c) on the $Q=f\left(\log \left(J /\left(a \cdot \sigma_{0}\right)\right)\right.$ trajectories for compact specimens.

The introduction of normalization in the graphical presentation of changes in $Q$-stress values allows to draw the following conclusions. The longer the crack, the smaller the $Q$-stress value at the same normalized external load, expressed with the help of the $J$-integral as an argument calculated as $\log \left(J /\left(a \cdot \sigma_{0}\right)\right)$ - Fig.10a. The shorter the crack, the $Q=f\left(\log \left(J /\left(a \cdot \sigma_{0}\right)\right)\right)$ curves are arranged lower, with the same material characteristics (Fig.10a). It should be noted that the $Q$-stress level is independent of the relative crack length in the range of very low external loads $\left(P / P_{0}=0.50\right)$. In the case of the impact of the yield point on the distribution of $Q=f\left(\log \left(J /\left(a \cdot \sigma_{0}\right)\right)\right)$ curves, it should be noted that the greater the yield point, the lower location of the $Q=f\left(\log \left(J /\left(a \cdot \sigma_{0}\right)\right)\right)$ curves (Fig.10b), however with increase in external load $\left(P / P_{0}>0.75\right)$, no influence of normalized external load on $Q$-stress level (Fig.10b) is observed. In the range of small external loads $\left(P / P_{0}<0.75\right)$, higher $Q$-stress values are observed for specimens characterized by lower yield strength, assuming that the assessment is carried out for a normalized external load expressed in the level of $J$-integral (Fig.10b). This means that $\mathrm{C}(\mathrm{T})$ specimens described with a material with a low yield strength are characterized by a higher level of in-plane constraints (expressed in $Q$-stresses) in the range of small external loads - Fig.10b. The introduction of normalization of the argument for the graphical presentation of $Q$-stress changes in terms of the assessment of the impact of the strain hardening exponent leads to similar conclusions (Fig.10c). The higher the level of material hardening, the $Q=f\left(\log \left(J /\left(a \cdot \sigma_{0}\right)\right)\right)$ curves are arranged higher (Fig.10c). The evident influence of the strain hardening exponent on the $Q$-stress value as the function of the $\log \left(J /\left(a \cdot \sigma_{0}\right)\right)$ argument is characteristic for external loads meeting the condition $P / P_{0} \leq 1.25$. A further increase in the external load level allows to state that the distribution of $Q=f\left(\log \left(J /\left(a \cdot \sigma_{0}\right)\right)\right)$ curves does not depend on the level of material hardening (Fig.10c).

\subsection{Large strain assumption}

Performing numerical analysis using the assumption of large strains and displacements leads to avoiding singularity in stress distributions, which as we know in real constructions are not infinite - they have a certain level $[13,14,18,20,24]$. 
a)

$C(T)$ plane strain $W=40 \mathrm{~mm}$ a/ $W=0.05$ $\sigma_{0}=500 \mathrm{MPa} \quad \mathrm{n}=10 \quad \mathrm{E}=206 \mathrm{GPa} \quad \mathrm{v}=0.3$

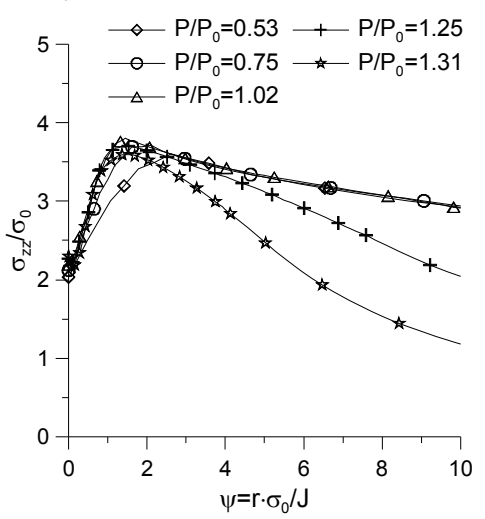

d)

$C(T)$ plane strain $W=40 \mathrm{~mm}$ a/ $W=0.05$ $\sigma_{0}=500 \mathrm{MPa} \quad \mathrm{n}=10 \quad \mathrm{E}=206 \mathrm{GPa} \quad \mathrm{v}=0.3$

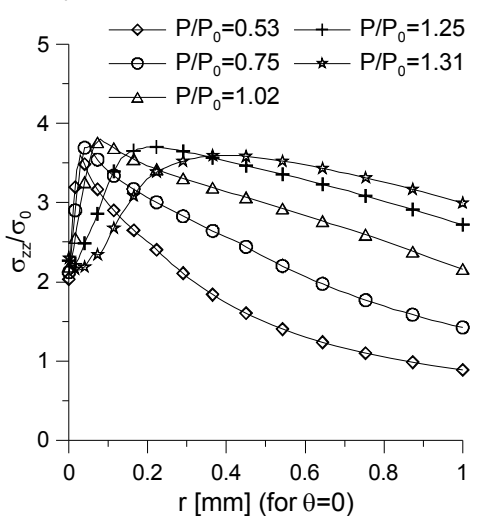

b) $C(T)$ plane strain $\quad W=40 \mathrm{~mm} \quad \mathrm{a} / \mathrm{W}=0.20$
$\sigma_{0}=500 \mathrm{MPa} \quad \mathrm{n}=10 \quad \mathrm{E}=206 \mathrm{GPa} \quad \mathrm{v}=0.3$

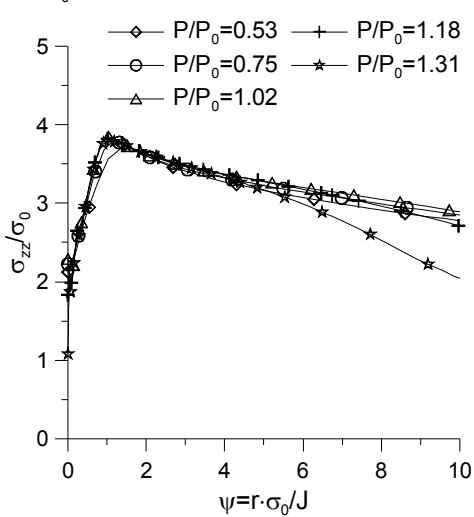

e)

$C(T)$ plane strain $W=40 \mathrm{~mm} \quad a / W=0.20$ $\sigma_{0}=500 \mathrm{MPa} \quad \mathrm{n}=10 \quad \mathrm{E}=206 \mathrm{GPa} \quad \mathrm{v}=0.3$

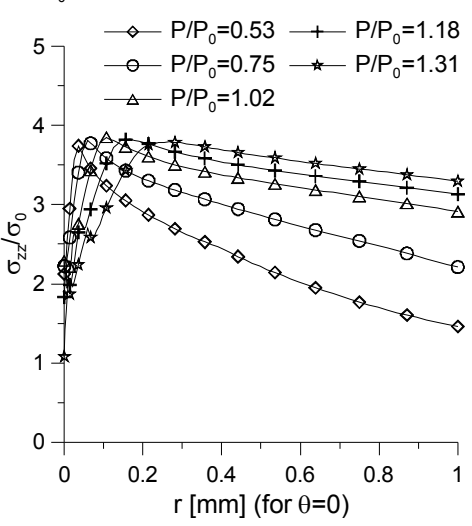

c)

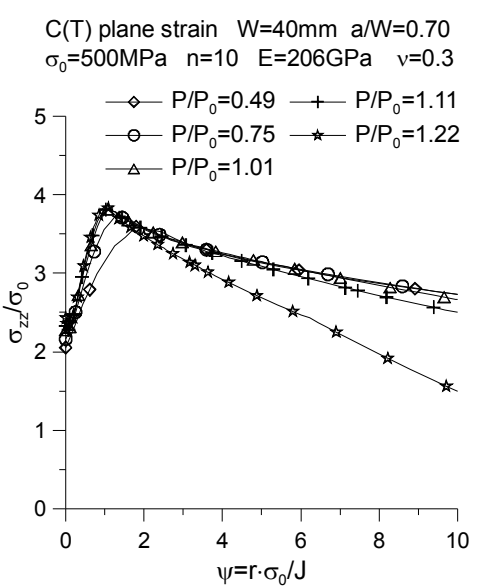

f)

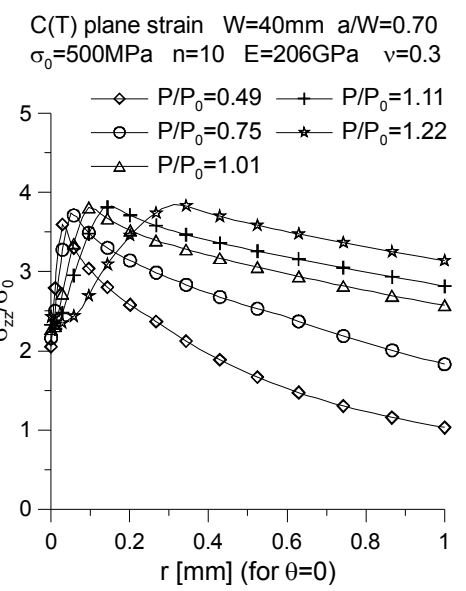

Fig.11. The influence of the level of external load on crack opening stress $\sigma_{z z}$ for $\mathrm{C}(\mathrm{T})$ specimens dominated by plane strain (calculations for large strain assumptions): a, b, c - the stress distribution in the function normalized distance from crack tip $\left(\sigma_{z z} / \sigma_{0}=f\left(r \cdot \sigma_{0} / J\right)\right)$; d, e, f - the stress distribution in the function physical distance from crack tip $\left(\sigma_{z z} / \sigma_{0}=f(r)\right)$.

Figure 11 shows the effect of external loading on the stress distribution that opens fracture surfaces in $\mathrm{C}(\mathrm{T})$ specimens, differing in the relative crack length. The normalized level of stress opening the fracture surfaces was presented as a function of the normalized position relative to the crack tip, denoted by $\psi$ (the physical distance from the crack tip $r$ was normalized by the quotient of $J$-integral and yield point $\sigma_{0}$ ) - Figs $11 \mathrm{a}-\mathrm{c}$ and as a function of the physical location - distance $r$ from the crack tip - Figs 11d-f. The analysis of Fig. 11 indicates that in the range of the considered external load, the stresses opening the crack surfaces reach a maximum at the normalized distance from the crack tip $\psi=(1 \div 2)$, wherein the change of maximum stress values opening the fracture surfaces is small (Figs 11a-c). Thus, it is possible to speak of an almost constant value of the maximum stresses opening the fracture surfaces, whose normalized position $\psi$ in the considered range of external loads is also almost unchanged (Figs 11a-c). The presented observations are confirmed by the analysis of the second part of Fig. 11 - Figs 11d-f. It turns out that for the considered range of external loads, the level of maximum stresses opening the fracture surfaces remains almost constant (Figs 11d-f). The influence of external load is important for the analysis of the physical location of the maximum stress opening the fracture surfaces - the higher the level of external load, the farthest occur from the crack tip the maximum opening crack stress (Figs 11d-f). 
Summing up, it should be noted that the stresses opening the crack surface for the considered range of external loads reach a maximum that is almost independent of the external load - along with the increase in external load only the physical position of this maximum denoted by $r$ is changed (Figs 11d-f and Fig.12), which after normalization by the quotient of the $J$-integral and the yield point $\sigma_{0}$ (which can be written as $\left.\psi=r \cdot \sigma_{0} / J\right)$ is also independent of the external load. The graphical distribution of the stress opening the fracture surfaces for the entire $\mathrm{C}(\mathrm{T})$ specimens is presented in Fig.12, along with the enlargement of the areas located close to the crack tip.

a)

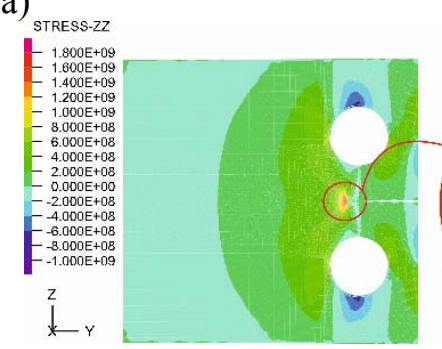

c)

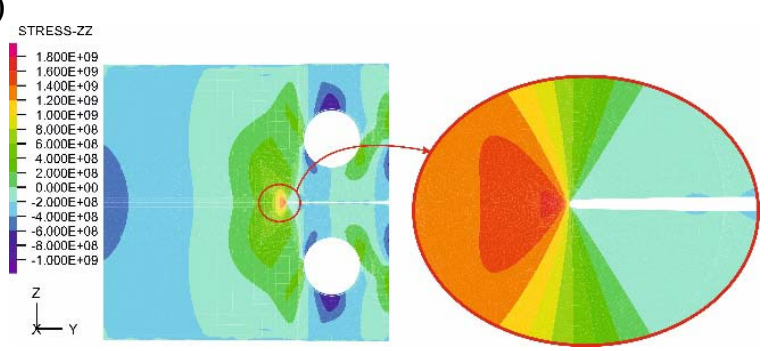

e)

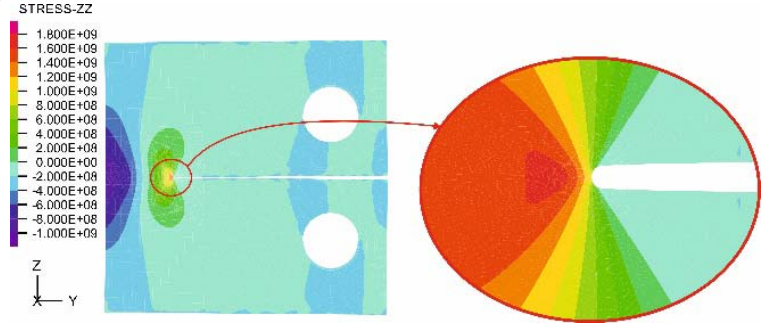

b)

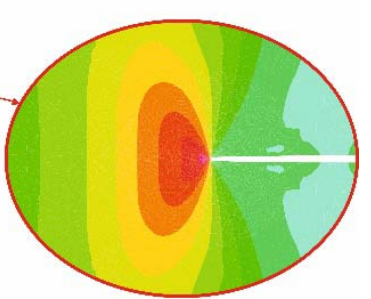

d)
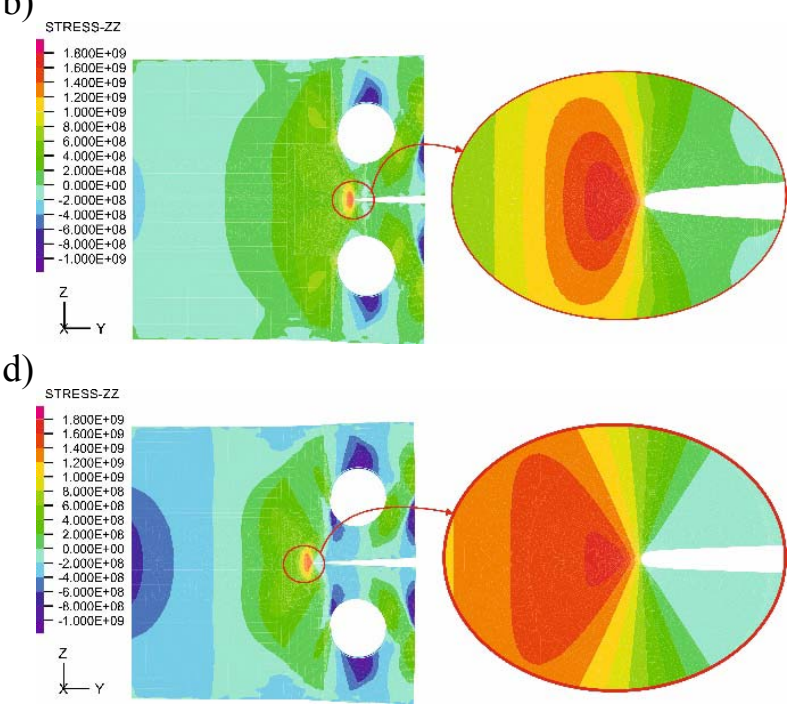

f)

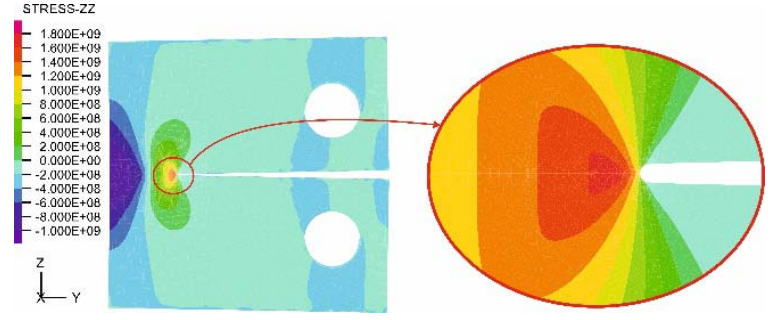

Fig.12. The distribution of the maximum crack opening stress $\sigma_{z z}$ for $C(T)$ specimens dominated by plane strain (calculations for large strain assumptions) for material characterized by $n=10, \sigma_{0}=500 \mathrm{MPa}$, $\mathrm{E}=206 \mathrm{GPa}, v=0.3: \mathrm{a}, \mathrm{b}-$ the $\sigma_{z z}$ stress distribution for $\mathrm{C}(\mathrm{T})$ specimen characterized by $a / W=0.05$, for $P / P_{0}=\{1.00,1.31\}$ respectively; $\mathrm{c}, \mathrm{d}-$ the $\sigma_{z z}$ stress distribution for $\mathrm{C}(\mathrm{T})$ specimen characterized by $a / W=0.20$, for $P / P_{0}=\{1.00,1.31\}$ respectively; e, $\mathrm{f}-$ the $\sigma_{z z}$ stress distribution for $\mathrm{C}(\mathrm{T})$ specimen characterized by $a / W=0.70$, for $P / P_{0}=\{1.00,1.22\}$ respectively.

Another numerically considered parameter is the effective stresses determined according to the Huber-Misses-Hencky hypothesis - Fig.13. The analysis of the results showed that as the crack tip moves closer the level of effective stress increases. Considering the changes of effective stresses in the function of a normalized position relative to the crack tip (Figs 13a-c), it is noticeable that there is no impact of the external load on the distribution of effective stresses in the load range $P / P_{0}=(0.75 \div 1.31)$ in the range of normalized distances $\psi=(0 \div 5)$ - Figs 13a-c. However, when assessing the level of effective stresses in physical coordinates - the physical distance from the crack tip denoted as $r$ - it should be noted that the value of effective stresses increases with the increase of the external load (Figs 13d-f), assuming that it is measured in the same physical location near the crack tip. 
a)

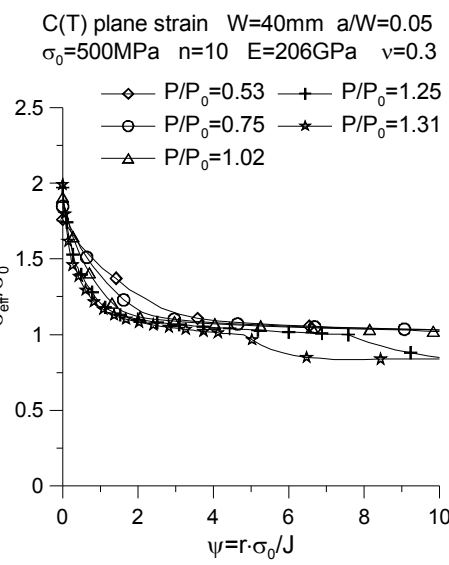

d)

$C(T)$ plane strain $W=40 \mathrm{~mm} \quad a / W=0.05$ $\sigma_{0}=500 \mathrm{MPa} \quad \mathrm{n}=10 \quad \mathrm{E}=206 \mathrm{GPa} \quad v=0.3$

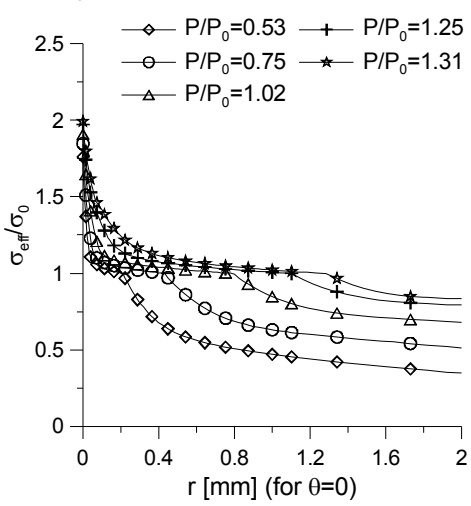

b)

c)

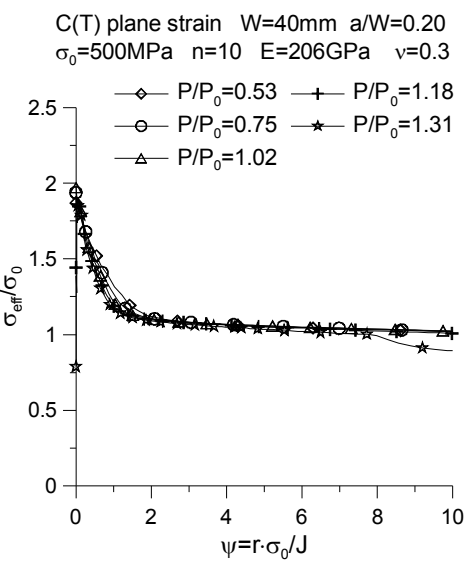

e)

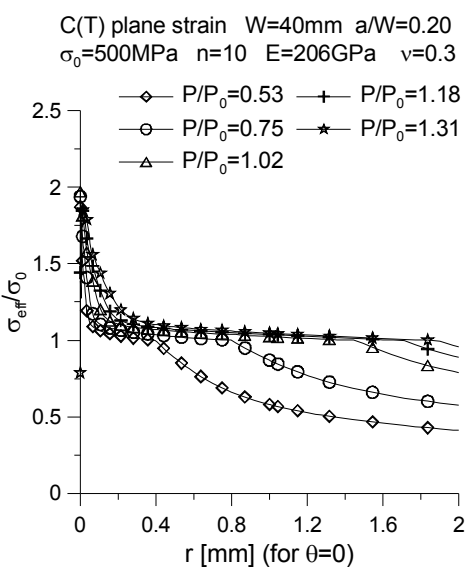

$C(T)$ plane strain $W=40 \mathrm{~mm} \quad a / W=0.70$ $\sigma_{0}=500 \mathrm{MPa} \quad n=10 \quad E=206 \mathrm{GPa} \quad v=0.3$

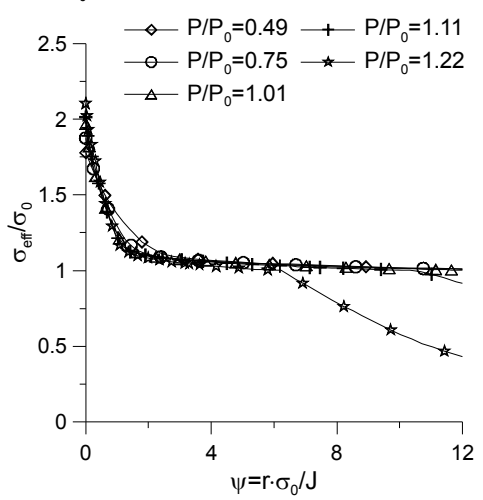

f)

$C(T)$ plane strain $W=40 \mathrm{~mm}$ a/ $\mathrm{W}=0.70$ $\sigma_{0}=500 \mathrm{MPa} \quad \mathrm{n}=10 \quad \mathrm{E}=206 \mathrm{GPa} \quad v=0.3$

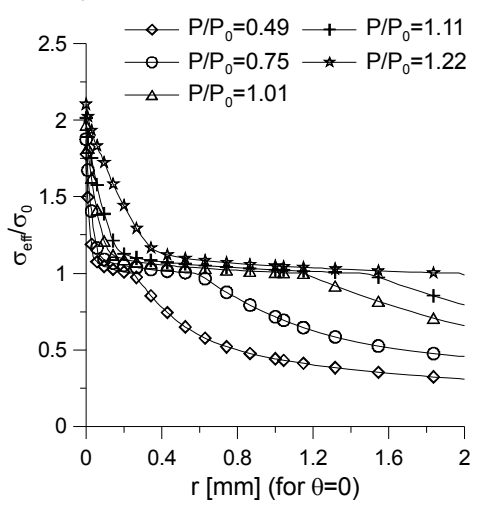

Fig.13. The influence of the level of external load on effective stress $\sigma_{\text {eff }}$ for $C(T)$ specimens dominated by plane strain (calculations for large strain assumptions): a, b, c - the stress distribution in the function normalized distance from crack tip $\left(\sigma_{e f f} / \sigma_{0}=f\left(r \cdot \sigma_{0} / J\right)\right)$; d, e, f - the stress distribution in the function physical distance from crack tip $\left(\sigma_{\text {eff }} / \sigma_{0}=f(r)\right)$.

The diagrams presented in Figs 13d-f should be analyzed along with the distributions of plastic zones shown in Fig.14. As can be seen in the diagrams presented in Figs 13d-f, starting with the crack tip, as the distance from it increases, the level of effective stress drops asymptotically to the value of $\sigma_{\text {eff }} \sigma_{0}=1.00$, after which the character of the changes undergoes transformation (Figs $13 \mathrm{~d}-\mathrm{f}$ ). The point at which the effective stress $\sigma_{\text {eff }}$ are less than yield stress, is the end point of the plastic zone which rises from the crack tip. In the analyzed geometry, the area in which the effective stresses calculated according to the Huber-Misses-Hencky hypothesis is equal to or greater than the yield point was accepted as plasticized. Thus, the last point on the graph can be treated as the radius of the plastic zone, denoted in the literature as $r_{p}$, which can be used to propose a new fracture criterion in order to estimate the actual fracture toughness, which was shown in [37]. 
a)

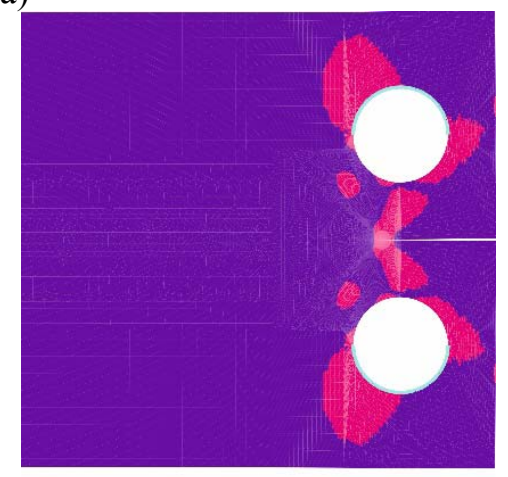

$$
\downarrow_{y}^{z} \text { - ELASTIC }
$$

d)

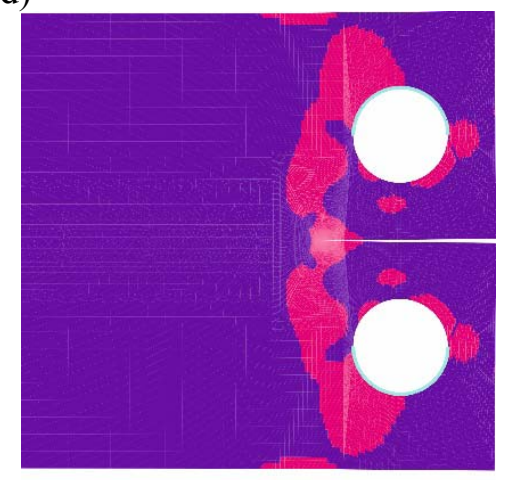

$$
\downarrow_{\text {Y }}^{Z} \text { F PLASTIC }
$$

g)

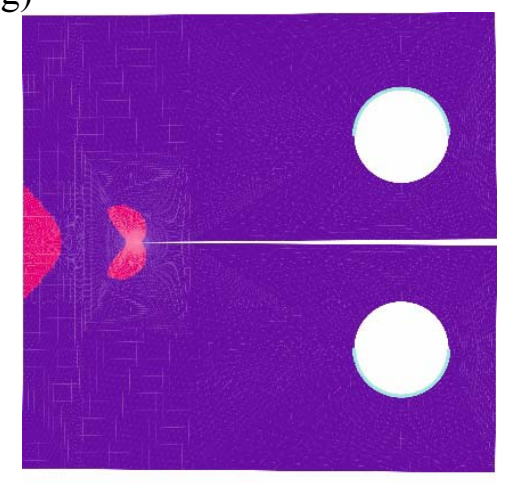
$\downarrow_{\chi_{Y}}^{Z}$ F PLASTIC b)

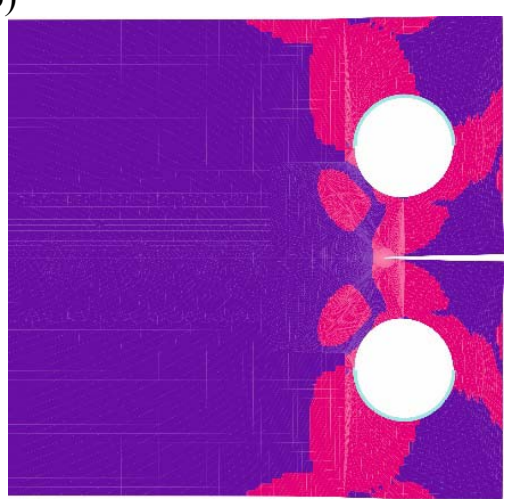

e)
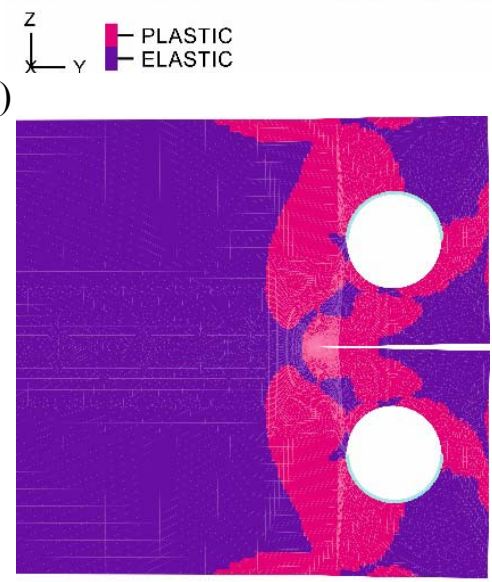

h)

$$
\downarrow_{\text {Y F F FASTIC }}^{Z}
$$

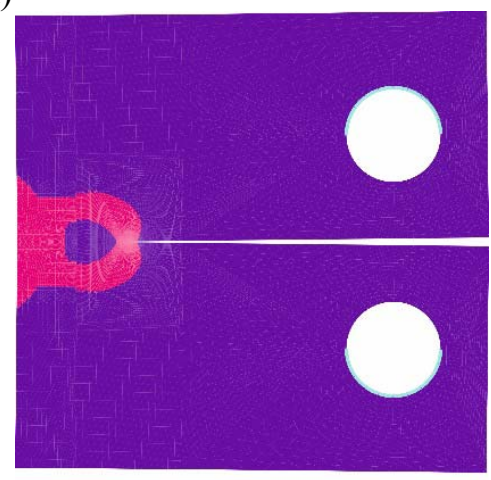

$\gtrless_{\text {Y }}^{z}$ FLLASTIC c)

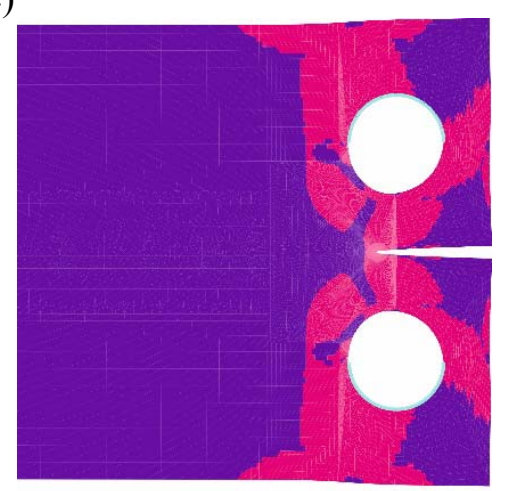

$\chi_{\text {Z Y FLASTIC }}^{z \text { PLASTIC }}$

f)

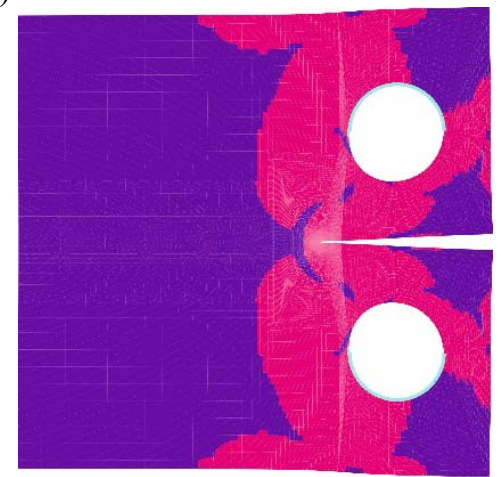

i)
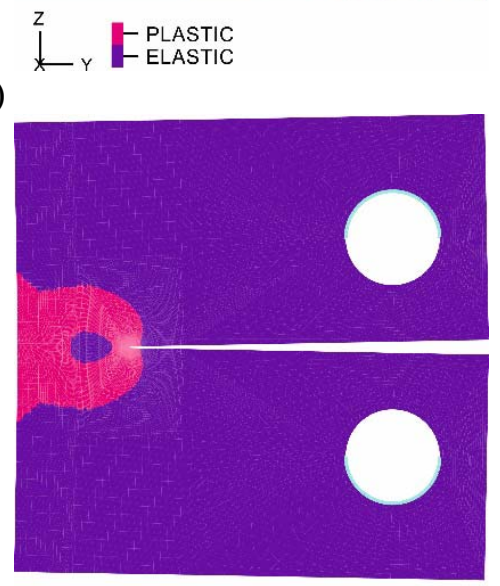

$\downarrow_{\text {Y }}^{Z}$ F PLASTIC

Fig.14. The influence of the level of external load on the shape and size of plastic zone for $C(T)$ specimens dominated by plane strain (calculations for small strain assumptions) for material characterized by $n=10, \sigma_{0}=500 \mathrm{MPa}, \mathrm{E}=206 \mathrm{GPa}, v=0.3: \mathrm{a}, \mathrm{b}, \mathrm{c}-$ the plastic zones for $\mathrm{C}(\mathrm{T})$ specimen characterized by $a / W=0.05$, for $P / P_{0}=\{1.00,1.25,1.35\}$ respectively; $\mathrm{d}$, e, $\mathrm{f}-$ the plastic zones for $\mathrm{C}(\mathrm{T})$ specimen characterized by $a / W=0.20$, for $P / P_{0}=\{1.00,1.15,1.25\}$ respectively; $\mathrm{g}, \mathrm{h}, \mathrm{I}-$ the plastic zones for $\mathrm{C}(\mathrm{T})$ specimen characterized by $a / W=0.70$ for $P / P_{0}=\{1.00,1.11,1.22\}$ respectively.

Increasing external load in a natural way causes the growth of the plastic zone near the crack tip (Fig.14), as well as the increase of accumulated plastic strain (Fig.15). Figure 15 presents the distributions of 
accumulated plastic strain $\varepsilon_{a p s}$ in the function of the real distance from the crack tip $r-\varepsilon_{a p s}=f(r)-$ Figs $15 \mathrm{~d}-\mathrm{f}$. The influence of external load can be lost, presenting the same distributions as a function of the normalized distance from the crack tip denoted by $\psi-\varepsilon_{a p s}=f\left(r \cdot \sigma_{0} / J\right)$. As the crack tip moves closer, the level of accumulated plastic strain increases, going to infinity.

a)

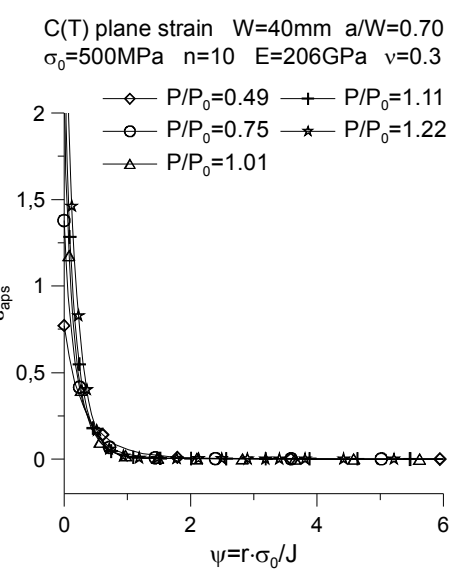

d)

$C(T)$ plane strain $W=40 \mathrm{~mm} \quad \mathrm{a} / \mathrm{W}=0.05$ $\sigma_{0}=500 \mathrm{MPa} \quad \mathrm{n}=10 \quad \mathrm{E}=206 \mathrm{GPa} \quad \mathrm{v}=0.3$

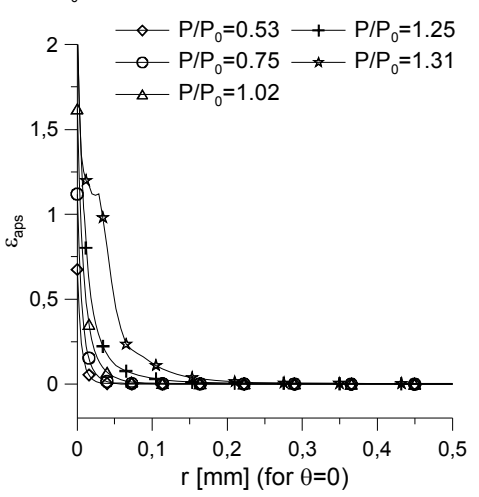

b)

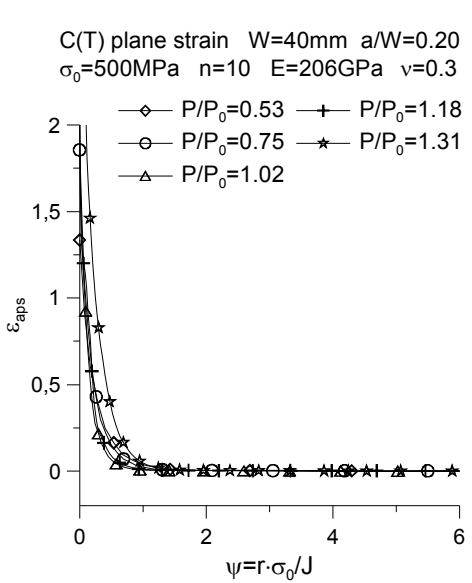

e)

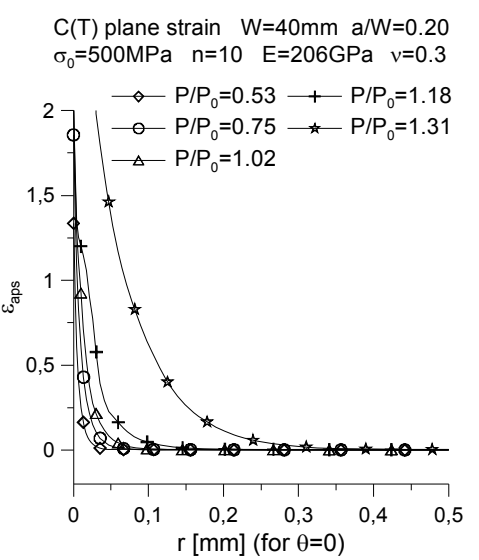

c)

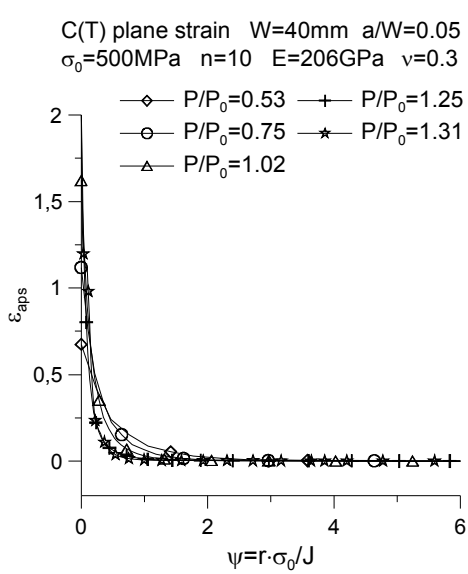

f)

$C(T)$ plane strain $W=40 \mathrm{~mm} \quad a / W=0.70$ $\sigma_{0}=500 \mathrm{MPa} \quad \mathrm{n}=10 \quad \mathrm{E}=206 \mathrm{GPa} \quad \mathrm{v}=0.3$

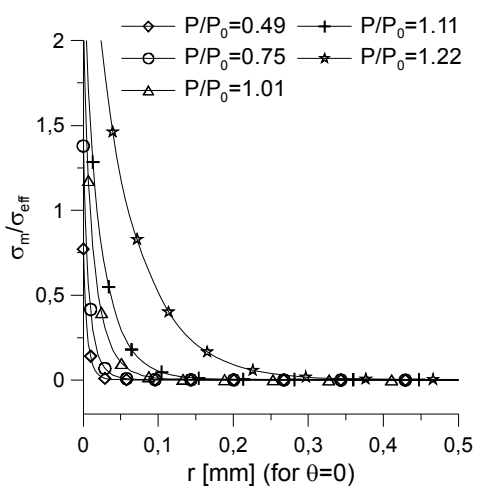

Fig.15. The influence of the level of external load on accumulated plastic strain $\varepsilon_{a p s}$ for $\mathrm{C}(\mathrm{T})$ specimens dominated by plane strain (calculations for large strain assumptions): $\mathrm{a}, \mathrm{b}, \mathrm{c}-$ the strain distribution in the function normalized distance from crack tip $\left(\varepsilon_{a p s}=f\left(r \cdot \sigma_{0} / J\right)\right)$; d, e, $\mathrm{f}-$ the stress distribution in the function physical distance from crack tip $\left(\varepsilon_{a p s}=f(r)\right)$.

Figure 16 presents changes in mean stresses normalized by the yield point $\left(\sigma_{m} / \sigma_{0}\right)$ as a function of the normalized distance from the crack tip (Figs 16a-c) and the physical distance from the crack tip (Figs 16d-f). The numerical results presented indicate that the mean stresses increase with the increase of the external load (Fig.16), and their distribution presented as a function of the normalized position from the crack tip indicates the occurrence of the maximum average stress in the distance $\psi=(1 \div 2)$ - Figs 16a-c, depending on the relative length of the crack and the material characteristics expressed by the yield point and the strain hardening exponent. It should be noted that the position of the maximum of the mean stresses considered as a function of the normalized distance from the crack tip (denoted by $\psi$ ) decreases as the external load increases, aiming for a steady value (Figs 16a-c), however the physical distance of this maximum of mean stresses increases as the external load increases (Figs 16d-f) - the physical maximum of the mean stresses moves away from the crack tip together with the increasing plastic zone, which is the result of the increasing external load. Analysis of the parameter $\sigma_{m} / \sigma_{0}$ may be quite significant, due to the 
possibility of using it in the process of estimating stresses $Q[13,14]$ - that parameter can be adapted to one of many fracture criteria in which the maximum crack opening stress were used [18], in order to take into account in the analysis the level of the stress triaxiality near the crack tip in elastic-plastic materials.

a)

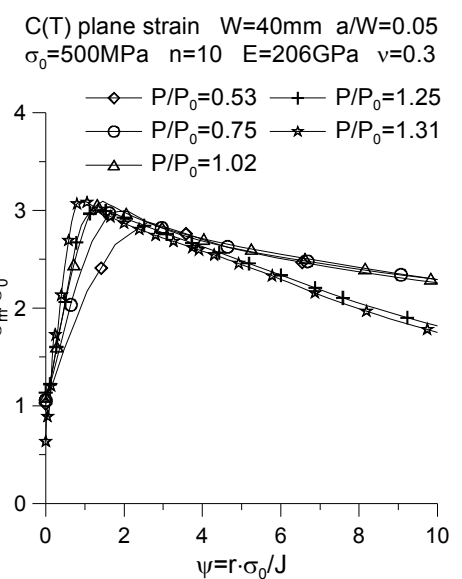

d)

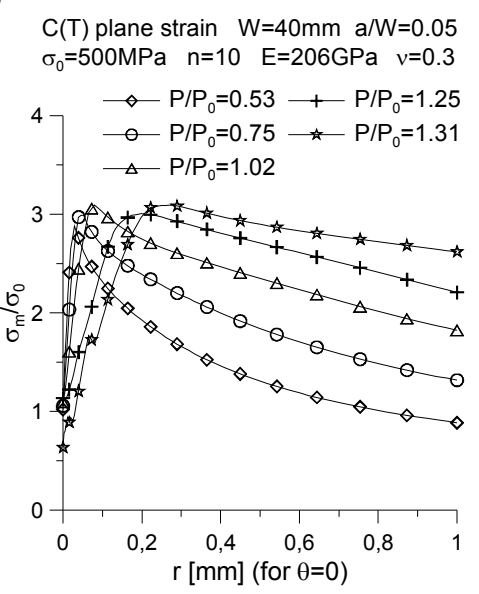

b)

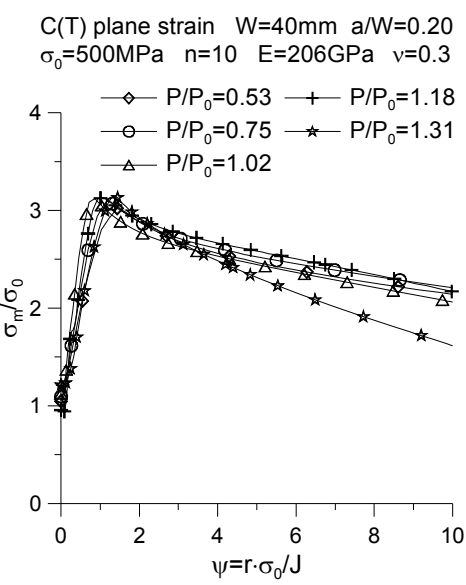

e)

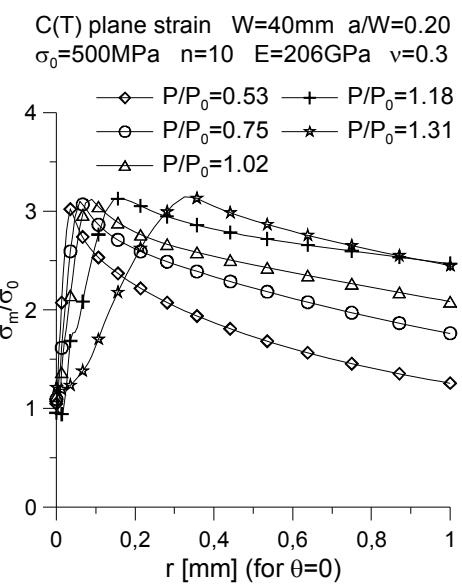

c)

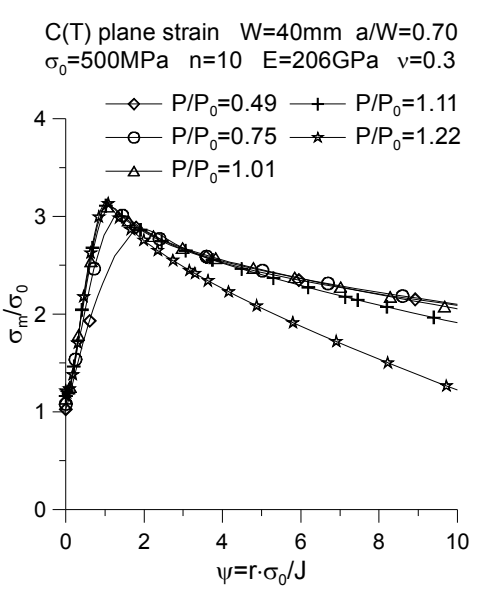

f)

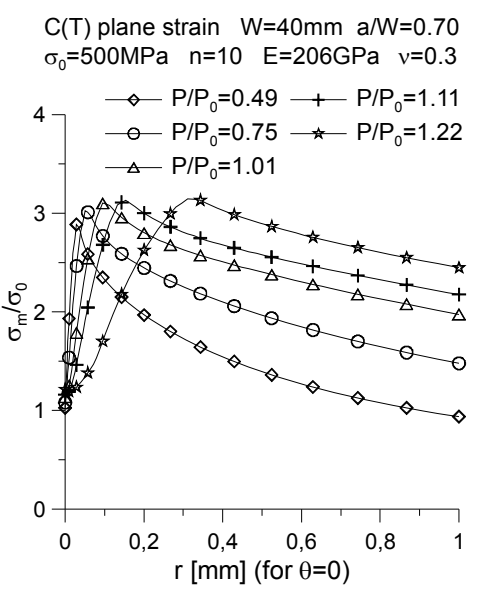

Fig.16. The influence of the level of external load on normal stress $\sigma_{m}$ for $\mathrm{C}(\mathrm{T})$ specimens dominated by plane strain (calculations for large strain assumptions): a, b, c - the strain distribution in the function normalized distance from crack tip $\left(\sigma_{m} / \sigma_{0}=f\left(r \cdot \sigma_{0} / \mathrm{J}\right)\right)$; d, e, f - the stress distribution in the function physical distance from crack tip $\left(\sigma_{m} / \sigma_{0}=f(r)\right)$.

From the point of view of assessing the real fracture toughness, as well as the level of geometric constraints (which are restrictions (i.e. limits) that the material of the loaded structural element puts on developing plastic deformations), it may be interesting to analyze the changes in the level of Maximum Crack Opening Stress (MCOS), denoted by $\xi_{0}=\sigma_{22} \max / \sigma_{0}$ (Fig.17) and their normalized position relative to the crack tip, denoted by $\psi_{o}=x_{22 \_ \text {max }} \cdot \sigma_{0} / J$ (Fig. 18 ).

Figure 17 shows the changes in the MCOS as a function of the increasing external load expressed by the $J$-integral. As shown earlier in Figure 1b, the level of MCOS increases with the increasing external load (in the range $P / P_{0}=\{0 \div 2\}$, and then reaches the saturation state (Fig.17). The weak influence of the crack length on the level of MCOS is observed, especially after reaching the saturation state (Fig. 17a). The same conclusions may apply to the normalized position of the MCOS near the crack tip (Fig.18a). Figure $17 \mathrm{~b}$ presents a very pronounced effect of the yield point on the level of MCOS. The smaller the yield point, the greater the values of the MCOS. In the range of small loads, the slight influence of the yield 
point applies to the normalized position of the MCOS (Fig.18b). The MCOS and their normalized position near the crack tip are clearly influenced by the degree of material hardening (Fig.17c and Fig.8c respectively) - the stronger material, the greater value of the MCOS and the smaller the value of their normalized position relative to the crack tip. Tables 1 and 2 present the numerically estimated values of the maximum stresses opening the fracture surfaces (marked as $\xi_{0}=\sigma_{22 \_ \text {max }} / \sigma_{0}$ ) with their normalized position relative to the crack tip (denoted as $\psi_{0}=x_{22 \_} \max \cdot \sigma_{0} / J$ ) - these results represent fixed values visible on the $\xi_{o}=f(J)$ and $\psi_{0}=f(J)$ graphs, respectively.

a)

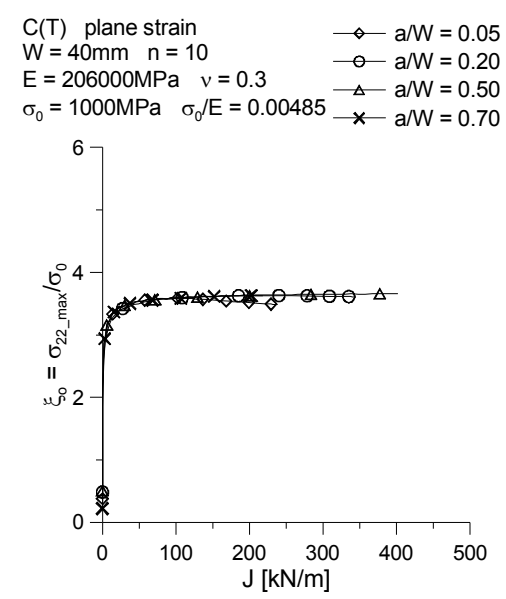

b)

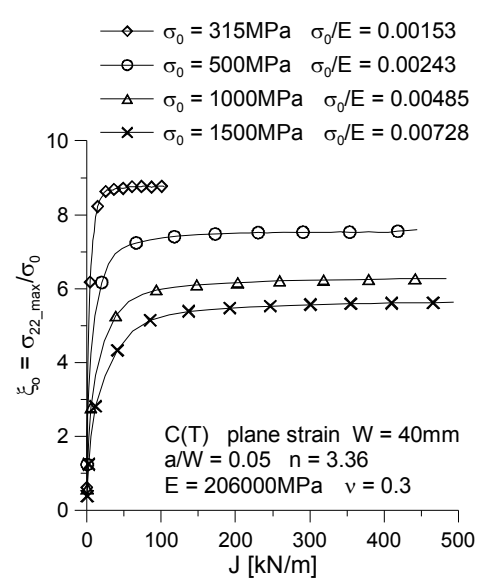

c)

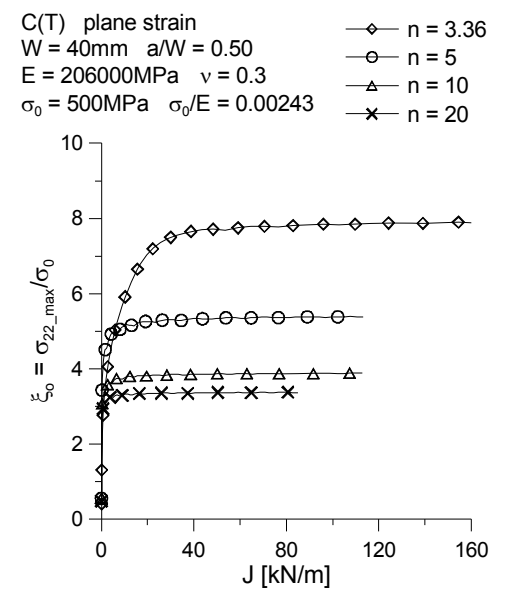

Fig.17. The influence of the relative crack length (a), yield stress (b) and strain hardening exponent (c) on the maximum crack opening stress $\left(\xi_{o}=\sigma_{22} \max / \sigma_{0}\right)$ for compact specimens - results for the whole spectrum of external load.

a)

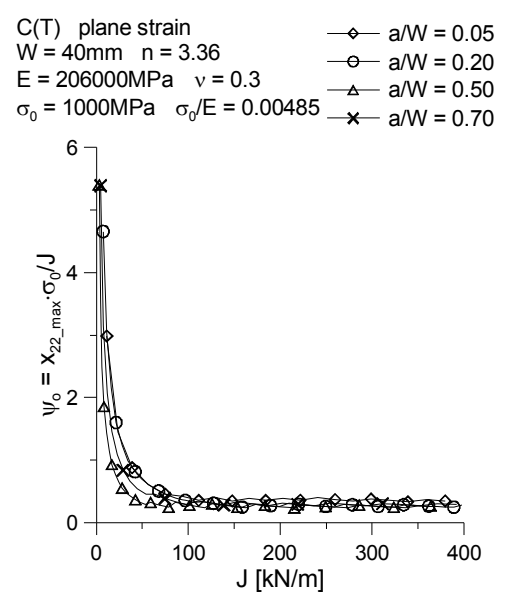

b)

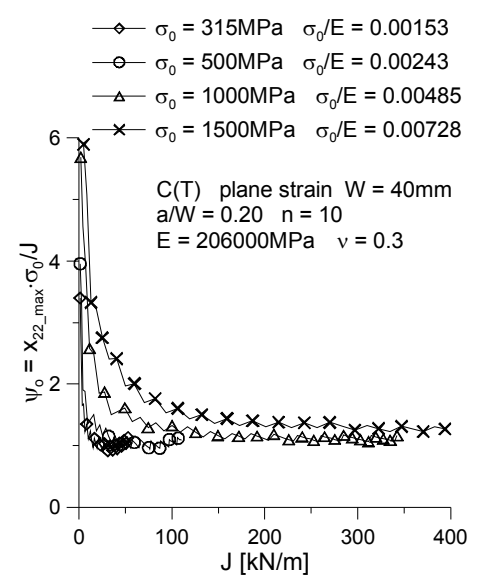

c)

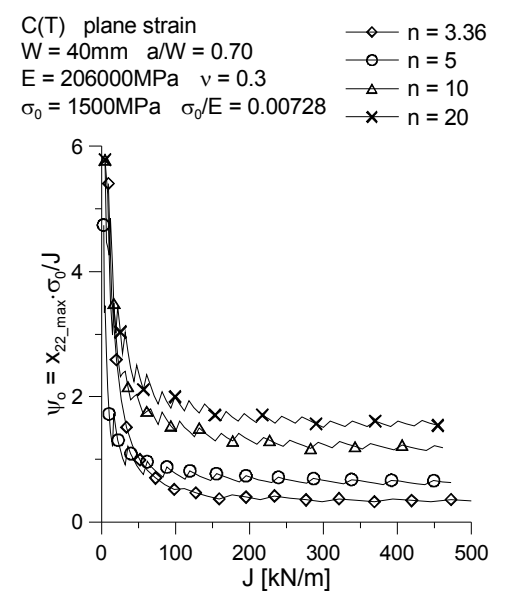

Fig.18. The influence of the relative crack length (a), yield stress (b) and strain hardening exponent (c) on the normalized position from the crack tip of the maximum crack opening stress $\left(\psi_{o}=x_{22} \max _{2} \cdot \sigma_{0} / J\right)$ for compact specimens - results for the whole spectrum of external load. 
Table 1. Numerically estimated values of maximum stress opening crack surfaces $\xi_{0}=\sigma_{22} \max \alpha \sigma_{0}$ for the state of saturation of curves $\xi_{o}=\xi_{o}(J)$ for $\mathrm{C}(\mathrm{T})$ specimens dominated by the plane strain state.

\begin{tabular}{|c|c|c|c|c|c|c|c|c|c|}
\hline \multicolumn{9}{|c|}{$\sigma_{0}=315 \mathrm{MPa} \quad \sigma_{0} / \mathrm{E}=0.00153$} & \multicolumn{5}{c|}{$\sigma_{0}=500 \mathrm{MPa} \quad \sigma_{0} / \mathrm{E}=0.00243$} \\
\hline$n$ & $a / W=0.05$ & $a / W=0.20$ & $a / W=0.50$ & $a / W=0.70$ & $n$ & $a / W=0.05$ & $a / W=0.20$ & $a / W=0.50$ & $a / W=0.70$ \\
\hline 3.36 & 8.759164 & 8.875839 & 8.957196 & 9.070496 & 3.36 & 7.527109 & 7.771978 & 7.878552 & 8.08214 \\
\hline 5 & 5.637336 & 5.761491 & 5.866615 & 5.834185 & 5 & 5.149182 & 5.282861 & 5.366404 & 5.231959 \\
\hline 10 & 3.805455 & 3.950204 & 4.045443 & 3.976293 & 10 & 3.657894 & 3.811541 & 3.87109 & 3.843521 \\
\hline 20 & 3.219771 & 3.378165 & 3.441704 & 3.411825 & 20 & 3.189682 & 3.327133 & 3.364317 & 3.356592 \\
\hline \multicolumn{6}{|c|}{$\sigma_{0}=1000 \mathrm{MPa} \sigma_{0} / \mathrm{E}=0.00485$} & \multicolumn{5}{c|}{$\sigma_{0}=1500 \mathrm{MPa} \sigma_{0} / \mathrm{E}=0.00728$} \\
\hline$n$ & $a / W=0.05$ & $a / W=0.20$ & $a / W=0.50$ & $a / W=0.70$ & $n$ & $a / W=0.05$ & $a / W=0.20$ & $a / W=0.50$ & $a / W=0.70$ \\
\hline 3.36 & 6.261961 & 6.409084 & 6.501177 & 6.573641 & 3.36 & 5.625672 & 5.731875 & 5.712908 & 5.737346 \\
\hline 5 & 4.607296 & 4.677846 & 4.740952 & 4.597552 & 5 & 4.332705 & 4.380931 & 4.354168 & 4.317984 \\
\hline 10 & 3.513294 & 3.61835 & 3.65014 & 3.617777 & 10 & 3.444042 & 3.510194 & 3.5101 & 3.480833 \\
\hline 20 & 3.182751 & 3.25234 & 3.292362 & 3.27191 & 20 & 3.147594 & 3.216597 & 3.222995 & 3.214645 \\
\hline
\end{tabular}

Table 2. Numerically estimated values of normalized position near the crack tip (denoted by $\psi_{0}$ ) of the maximum stress opening crack surfaces $\xi_{0}=\sigma_{22} \max / \sigma_{0}$ for the state of saturation of curves $\psi_{0}=\psi_{0}(J)$ for $\mathrm{C}(\mathrm{T})$ specimens dominated by the plane strain state.

\begin{tabular}{|c|c|c|c|c|c|c|c|c|c|c|}
\hline \multicolumn{9}{|c|}{$\sigma_{0}=315 \mathrm{MPa}$} & $\sigma_{0} / \mathrm{E}=0.00153$ & \multicolumn{5}{c|}{$\sigma_{0}=500 \mathrm{MPa} \quad \sigma_{0} / \mathrm{E}=0.00243$} \\
\hline$n$ & $a / W=0.05$ & $a / W=0.20$ & $a / W=0.50$ & $a / W=0.70$ & $n$ & $a / W=0.05$ & $a / W=0.20$ & $a / W=0.50$ & $a / W=0.70$ \\
\hline 3.36 & 0.209949 & 0.170728 & 0.189151 & 0.205076 & 3.36 & 0.261104 & 0.199359 & 0.198109 & 0.22838 \\
\hline 5 & 0.499667 & 0.393716 & 0.43742 & 0.451438 & 5 & 0.641399 & 0.475459 & 0.460588 & 0.547445 \\
\hline 10 & 1.449834 & 1.041845 & 0.93387 & 1.058766 & 10 & 1.464255 & 1.057733 & 0.942647 & 1.037846 \\
\hline 20 & 2.120104 & 1.531334 & 1.294685 & 1.410907 & 20 & 2.155575 & 1.447721 & 1.33659 & 1.389189 \\
\hline \multicolumn{6}{|c|}{$\sigma_{0}=1000 \mathrm{MPa} \sigma_{0} / \mathrm{E}=0.00485$} & \multicolumn{5}{c|}{$\sigma_{0}=1500 \mathrm{MPa} \quad \sigma_{0} / \mathrm{E}=0.00728$} \\
\hline$n$ & $a / W=0.05$ & $a / W=0.20$ & $a / W=0.50$ & $a / W=0.70$ & $n$ & $a / W=0.05$ & $a / W=0.20$ & $a / W=0.50$ & $a / W=0.70$ \\
\hline 3.36 & 0.345377 & 0.262019 & 0.2607 & 0.288837 & 3.36 & 0.402368 & 0.309705 & 0.308995 & 0.325056 \\
\hline 5 & 0.692499 & 0.582286 & 0.544415 & 0.638787 & 5 & 0.749601 & 0.624809 & 0.650828 & 0.645949 \\
\hline 10 & 1.47332 & 1.118237 & 1.07271 & 1.116932 & 10 & 1.381901 & 1.226061 & 1.236787 & 1.225757 \\
\hline 20 & 2.288411 & 1.578627 & 1.4857 & 1.439393 & 20 & 2.074317 & 1.688819 & 1.761894 & 1.592888 \\
\hline
\end{tabular}

\section{Approximation of the selected numerical results}

The analysis presented in the paper, in addition to the characteristics of mechanical fields, provides information on parameters that are commonly considered as the measurement of in-plane constraints, which are the answer of the materials for increasing plastic deformation, which results from the growing external load. Among these measures, the $Q$-stress defined by O'Dowd and the maximum stresses opening the crack surfaces $\xi_{0}=\sigma_{22} \max / \sigma_{0}$ and their normalized position from the crack tip $\psi_{0}=x_{22} \max _{0} \cdot \sigma_{0} / J$ were highlighted in the paper. These quantities, as already mentioned before, can be used in predicting the real fracture toughness, using properly defined fracture criterion $[18,19,40]$. As shown above, the estimation of parameters of geometrical in-plane constraints requires the proper elaboration of the numerical model, which guarantees the convergence of the solution and the analysis of the obtained numerical results (post-processing). Therefore, it is proposed to catalog the obtained numerical solutions and to approximate selected ones, which for many other basic geometries shown in the FITNET [25] procedures was presented in [21-24].

Based on the previously developed method of analysis, obtained during numerical calculations of the $Q$-stress changes as the function of $\log \left(J /\left(a \cdot \sigma_{0}\right)\right)$ (in other words $Q=f\left(\log \left(J /\left(a \cdot \sigma_{0}\right)\right)\right)$ curves), are described by the third-order polynomial - formula (4.1) 


$$
Q=A_{1}+A_{2} \cdot\left(\log \left(\frac{J}{a \cdot \sigma_{0}}\right)\right)+A_{3} \cdot\left(\log \left(\frac{J}{a \cdot \sigma_{0}}\right)\right)^{2}+A_{4} \cdot\left(\log \left(\frac{J}{a \cdot \sigma_{0}}\right)\right)^{3}
$$

where $A_{1}, A_{2}, A_{3}$ and $A_{4}$ are approximation factors. For the models of C(T) specimens tested in the study differing in material characteristics (different strain hardening exponent $n$, different yield point $\sigma_{0}$ ) and relative crack length $a / W$, the determination coefficient $R^{2}$ obtained during approximation was generally greater than 0.95. Example approximation results are presented in Tab.3. In Fig. 19a, the convergence between selected numerical solutions and the approximation results for two $\mathrm{C}(\mathrm{T})$ specimens containing short cracks $(a / W=0.20)$ is shown graphically, however, made very strongly and very weakly hardening material (the value of the strain hardening exponent is $n=3.36$ and $n=20$, respectively).

Table 3. Approximation coefficients of the formula (4.1), necessary to estimate the $Q$-stresses for C(T) specimens dominated by the plane strain state (selected approximation results).

\begin{tabular}{|c|c|c|c|c|c|c|c|c|c|c|c|}
\hline \multirow{6}{*}{ 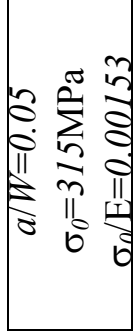 } & $n$ & 3.36 & 5 & 10 & 20 & \multirow{6}{*}{ 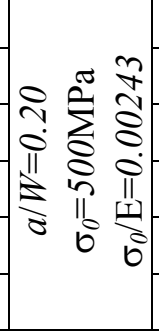 } & $n$ & 3.36 & 5 & 10 & 20 \\
\hline & $A_{1}$ & -6.404 & -9.854 & -3.600 & -2.463 & & $A_{1}$ & -20.328 & -32.795 & -11.818 & -187.137 \\
\hline & $A_{2}$ & -13.776 & -25.999 & -7.361 & -4.473 & & $A_{2}$ & -39.306 & -68.766 & -22.086 & -340.059 \\
\hline & $A_{3}$ & -8.913 & -21.740 & -4.825 & -2.617 & & $A_{3}$ & -24.915 & -47.520 & -13.654 & -205.933 \\
\hline & $A_{4}$ & -1.807 & -5.881 & -1.039 & -0.504 & & $A_{4}$ & -5.175 & -10.845 & -2.802 & -41.567 \\
\hline & $R^{2}$ & 0.984 & 0.988 & 0.996 & 0.997 & & $R^{2}$ & 0.989 & 0.996 & 0.997 & 0.957 \\
\hline \multirow{6}{*}{ 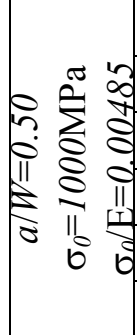 } & $n$ & 3.36 & 5 & 10 & 20 & \multirow{6}{*}{ 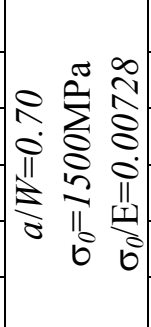 } & $n$ & 3.36 & 5 & 10 & 20 \\
\hline & $A_{1}$ & -8.648 & -7.390 & -6.646 & -8.368 & & $A_{1}$ & -14.423 & -13.248 & -10.860 & -12.785 \\
\hline & $A_{2}$ & -12.191 & -10.437 & -9.382 & -12.328 & & $A_{2}$ & -17.908 & -16.416 & -13.074 & -15.754 \\
\hline & $A_{3}$ & -5.755 & -4.890 & -4.350 & -5.971 & & $A_{3}$ & -7.518 & -6.847 & -5.277 & -6.484 \\
\hline & $A_{4}$ & -0.885 & -0.744 & -0.655 & -0.948 & & $A_{4}$ & -1.041 & -0.941 & -0.701 & -0.880 \\
\hline & $R^{2}$ & 0.991 & 0.995 & 0.994 & 0.994 & & $R^{2}$ & 0.994 & 0.995 & 0.998 & 0.996 \\
\hline
\end{tabular}

a)

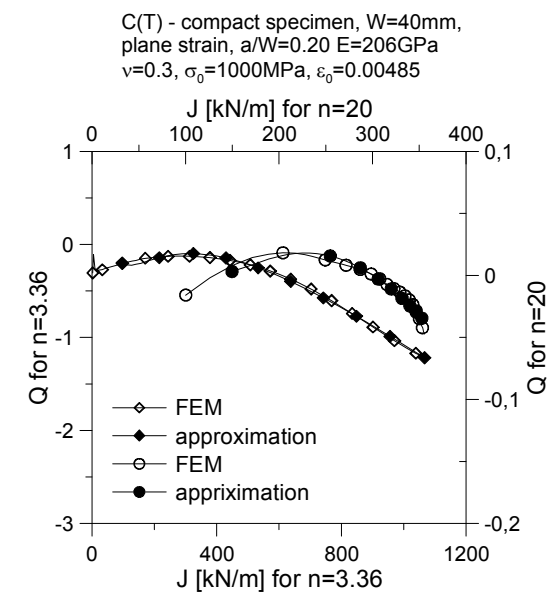

b)

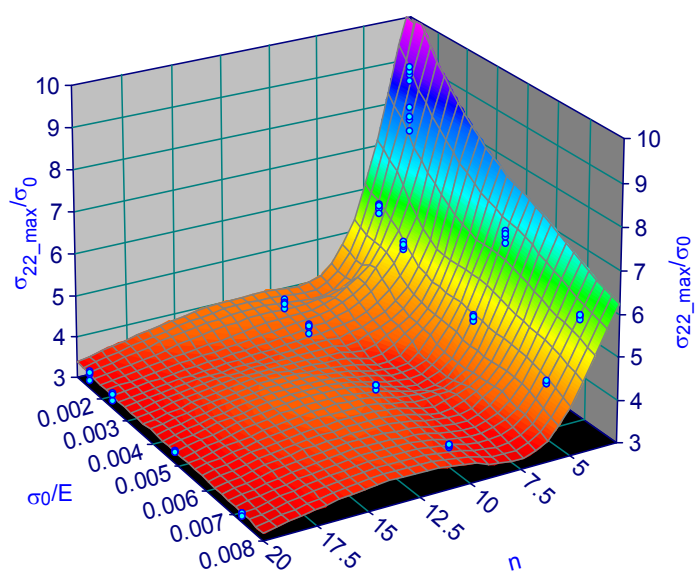

Fig.19. a) Comparison of the numerical results and their approximation for two selected $Q=f(J)$ curves for $\mathrm{C}(\mathrm{T})$ specimens; $\mathrm{b})$ Representation of the numerical results and approximation surface for maximum crack opening stress for the saturation state. 
Figure $19 \mathrm{~b}$ presents the representation of all the results obtained during numerical calculations in the range of estimating the value of the maximum stresses opening the fracture surfaces, denoted by $\xi_{o}=\sigma_{22 \_ \text {max }} / \sigma_{0}$. During the analysis, four such graphs $\xi_{o}=f\left(\sigma_{0} / \mathrm{E}, n\right)$ were drawn, separately for each of the relative crack length (these charts are not attached to the paper), after which a summary graph for all considered cases was drawn up, due to the low impact of the relative crack length $a / W$ on the saturation value of the maximum stress opening the fracture surfaces indicated by $\xi_{o}$ (Fig.17a). The analysis carried out by the author shows that the relative crack length $a / W$ has a very small effect on the level of maximum crack opening stress $\xi_{o}$. Referring values of $\xi_{o}$ for individual relative crack lengths from the range $a / W=\{0.05$, $0.20,0.50\}$ up to $\xi_{o}$ values characteristic for $a / W=0.70$ (for this relative crack length the highest value of maximum crack opening stress is observed), it can be stated, that for subsequent relative crack lengths from said set, the percent differences are $\{3.06 \%, 1.18 \%, 1.16 \%\}$, respectively. The biggest differences for the same material characteristics are observed for specimens characterized by very short cracks. For selected cases, these differences are around 5\%, and for some, up to $7 \%$. The resulting curvilinear surfaces - both for groups of $\mathrm{C}(\mathrm{T})$ specimens characterized by the same relative crack length as well as for the whole specimens population, are described by Eq.(4.2)

$$
\begin{aligned}
& \xi_{o}=A_{1}+\frac{A_{2}}{n}+A_{3} \cdot\left(\frac{\sigma_{0}}{E}\right)+\frac{A_{4}}{n^{2}}+A_{5} \cdot\left(\frac{\sigma_{0}}{E}\right)^{2}+ \\
& +\frac{A_{6}}{n} \cdot\left(\frac{\sigma_{0}}{E}\right)+\frac{A_{7}}{n^{3}}+A_{8} \cdot\left(\frac{\sigma_{0}}{E}\right)^{3}+\frac{A_{9}}{n} \cdot\left(\frac{\sigma_{0}}{E}\right)^{2}+\frac{A_{10}}{n^{2}} \cdot\left(\frac{\sigma_{0}}{E}\right)
\end{aligned}
$$

where $A_{1}, A_{2}, \ldots, A_{10}$ are approximation factors that are summarized in Tab.2. The determination coefficient $R^{2}$ of Eq.(4.2) to the estimated numerical values is generally greater than 0.98 .

Table 4. Approximation coefficients of the formula (4.2), necessary to estimate the maximum opening crack stress $\xi_{o}$ for $\mathrm{C}(\mathrm{T})$ specimens dominated by the plane strain state for the saturation state of the

\begin{tabular}{|c|c|c|c|c|c|c|}
\hline$a / W$ & $A_{1}$ & $A_{2}$ & $A_{3}$ & $A_{4}$ & $A_{5}$ & $A_{6}$ \\
\hline 0.05 & 3.081 & 8.166 & -239.434 & 53.386 & 94186 & -2924 \\
\hline 0.20 & 3.112 & 10.175 & -173.037 & 32.329 & 55065 & -2314 \\
\hline 0.50 & 3.270 & 10.960 & -292.857 & 28.805 & 82728 & -2245 \\
\hline 0.70 & 3.265 & 11.535 & -306.195 & 16.083 & 84832 & -2219 \\
\hline all $a / W$ & 3.182 & 10.209 & -252.881 & 32.651 & 79203 & -2426 \\
\hline$a / W$ & $A_{7}$ & $A_{8}$ & $A_{9}$ & $A_{10}$ & $R^{2}$ & \\
\hline 0.05 & -12.749 & -8503900 & 263870 & -3196 & 0.982 & \\
\hline 0.20 & 32.490 & -4650100 & 207479 & -3485 & 0.986 & \\
\hline 0.50 & 34.855 & -6518500 & 175384 & -2982 & 0.987 & \\
\hline 0.70 & 81.943 & -6725700 & 199786 & -3933 & 0.989 & \\
\hline all $a / W$ & 34.135 & -6599500 & 211630 & -3399 & 0.984 & \\
\hline
\end{tabular}
$\xi_{o}=f(J)$ curves.

The previous paragraph of the paper also shows the influence of material characteristics and the relative crack length on the system of $\psi_{0}=f(J)$ curves. The $\psi_{0}=f(J)$ curves also strive to reach the set value as the external load increases. The fixed value $\psi_{0}$ - the fixed value of the normalized position of the maximum crack opening stresses - also found application in the search for real fracture toughness - this parameter was 
used in several fracture criteria [18, 40]. For this reason, with a set of numerical results (Tab.2), approximation formulas can be given, allowing to estimate the value of the parameter $\psi_{0}$ depending on the relative crack length $a / W$, the strain hardening exponent $n$, for a given yield point $\sigma_{0}$

$$
\psi_{0}=\exp \left(A_{I}+\frac{A_{I I}}{\ln (n)}+\frac{A_{I I} \cdot \ln (a / W)}{(a / W)^{2}}\right)
$$

where by $A_{I}, A_{I I}$ and $A_{I I I}$ the approximation factors were denoted, which are given for data with a given yield point in Tab.5. The determination coefficient $R^{2}$ for subsequent data sets was greater than 0.99.

Table 5. Approximation coefficients of the formula (4.3), necessary to estimate the normalized position near the crack tip (denoted as $\psi_{0}$ ) of the maximum opening crack stress for $\mathrm{C}(\mathrm{T})$ specimens dominated by the plane strain state for the saturation state of the $\psi_{0}=f(J)$ curves.

\begin{tabular}{|c|c|c|c|c|}
\hline$\sigma_{0}[\mathrm{MPa}]$ & 315 & 500 & 1000 & 1500 \\
\hline$\sigma_{0} / \mathrm{E}$ & 0.00153 & 0.00243 & 0.00485 & 0.00728 \\
\hline$A_{I}$ & 0.4993 & 0.4595 & 1.6257 & 1.6663 \\
\hline$A_{I I}$ & -21.9916 & -19.6640 & -3.5852 & -3.4064 \\
\hline$A_{I I I}$ & -0.00665 & -0.00709 & -0.00031 & -0.00015 \\
\hline$R^{2}$ & 0.992 & 0.994 & 0.991 & 0.995 \\
\hline
\end{tabular}

\section{Summary}

Using the finite element method, the paper presented a comprehensive analysis of the in-plane constraints for the compact specimen. The level of the selected parameters of the in-plane constraints - like $Q$-stress and maximum crack opening stress and their position near the crack tip - was evaluated. A discussion was held about the influence of the material properties (yield stress, strain hardening exponent in the R-O law) and the relative crack length on the presented parameters of geometric constraints. The selected results for the $Q$-stress and maximum crack opening stress were approximated by mathematical formulas. The results of numerical calculations with the given approximation formulas presented in the paper may be useful in solving various engineering problems, which need to calculate he stress distribution near the crack tip, the real fracture toughness, or graph the $J-R$ curves.

\section{Acknowledgments}

The research reported herein was supported by a grant from the Faculty of Mechatronics and Machine Design at Kielce University of Technology (project No. 01.0.09.00/2.01.01.01.0027 MNSP.MKTM.17.002).

\section{Nomenclature}

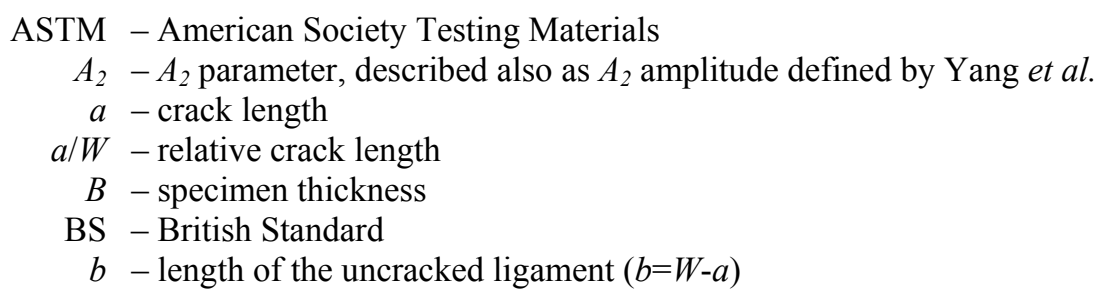




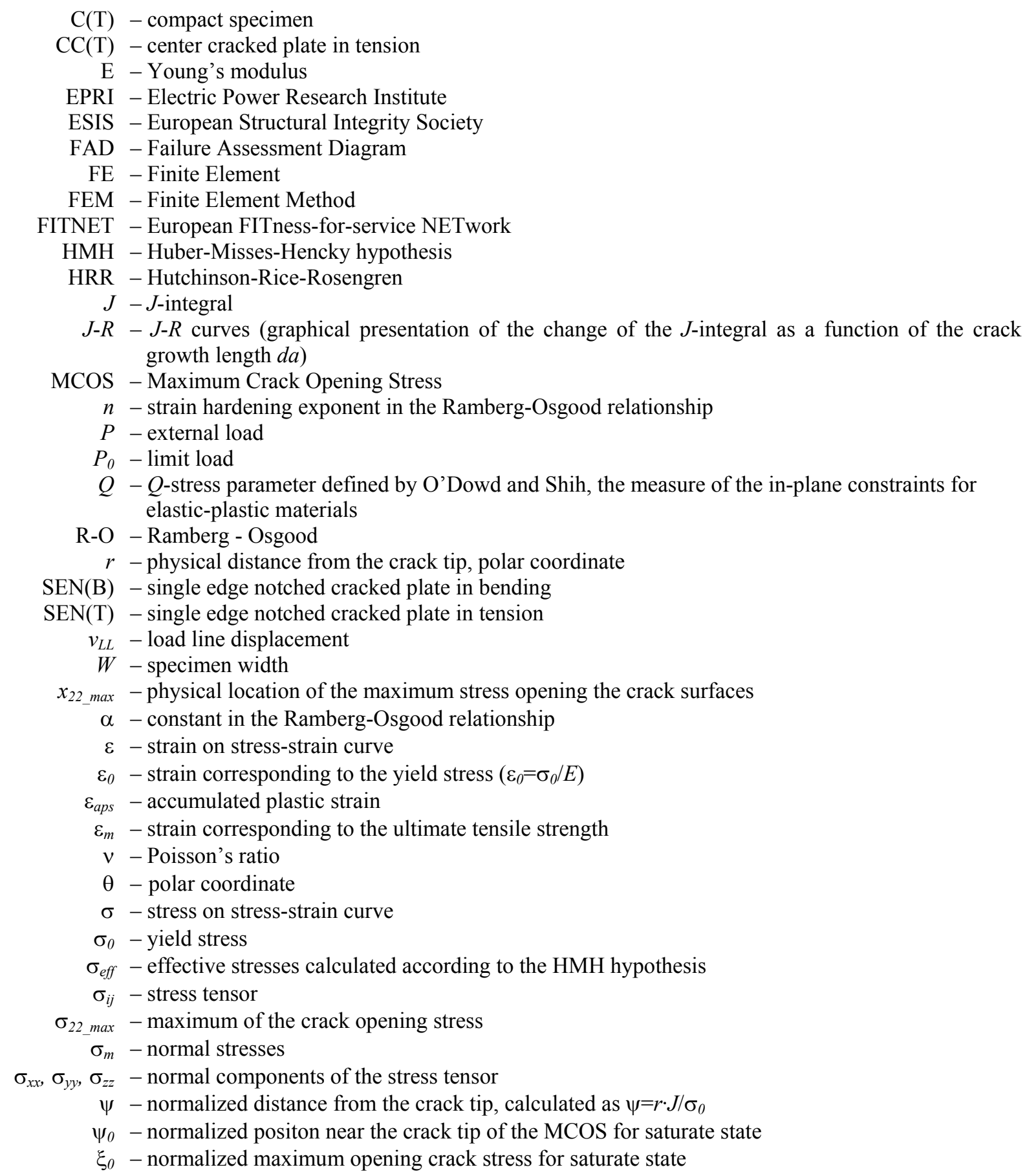

\section{References}

[1] ASTM (2005): ASTM E 1820-05 Standard Test Method for Measurement of Fracture Toughness. - American Society for Testing and Materials.

[2] ASTM (2011): ASTM E1921-11 Standard test method for determining of reference temperature $T_{0}$ for ferritic steels in the transition range. - American Society for Testing and Materials.

[3] BS 5762 (1979): Methods for crack opening displacement (COD) testing. - London: British Standards Institute. 
[4] BS 7448 (1991): Part 1. Fracture mechanics toughness tests: Part 1 - Method for determining of $K_{I c}$, critical CTOD and critical $J$ values of metallic materials. - London: British Standards Institute.

[5] PN-87/H-4335, Metals - Test method for measurement of the fracture toughness for plane strain conditions.

[6] Kornev V.M. and Demeshkin A.G. (2018): Quasi-brittle fracture of compact specimens with sharp notches and ushaped cuts. - Journal of Applied Mechanics and Technical Physics, vol.59, No.1, pp.120-131, DOI $10.1134 / \mathrm{S} 0021894418010157$.

[7] Kayamori Y. and Kawabata T. (2017): Evaluation of rotational deformation in compact specimens for CTOD fracture toughness testing. - Procedia Structural Integrity, vol.5, pp.286-293 DOI 10.1016/j.prostr.2017.07.135.

[8] Doddamani S. and Kaleemulla M. (2017): Fracture toughness investigations of Al6061-graphite particulate composite using compact specimens - Frattura ed Integrità Strutturale, vol.11, No.41, pp.484-490, DOI 10.3221/IGF-ESIS.41.60.

[9] Horstman R.T., Lieb K.C., Power B., Landes J.D., et al. (1979): Evaluation of the J integral for the compact specimen. - Journal of Testing and Evaluation, vol.7, No.5, pp.264-269. DOI 10.1520/JTE10222J.

[10] Shivakumar N. and Newman J.C. (1992): Verification of effective thicknesses for side-grooved compact specimens. - Engineering Fracture Mechanics 43(2), 1992, DOI 10.1016/0013-7944(92)90125-X, Source NTRS,

[11] Hu J.M., Cheng J., Albrecht P. and Joyce J. (1989): Ductile Crack Extension in Compact Specimens at Limit Load. - DOI 10.1016/B978-0-08-034341-9.50047-4, In book: Proceedings of The 7th International Conference On Fracture (ICF7).

[12] Zhu X.-K. and Joyce J.A. (2012): Review of fracture toughness ( $G, K, J, C T O D$, CTOA) testing and standardization. - Engineering Fracture Mechanics, vol.85, pp.1-46, DOI:10.1016/j.engfracmech.2012.02.001

[13] O'Dowd N.P. and Shih C.F. (1991): Family of crack-tip fields characterized by a triaxiality parameter - I. Structure of Fields. - J. Mech. Phys. Solids, vol.39, No.8, pp.989-1015.

[14] O'Dowd N.P. and Shih C.F. (1992): Family of crack-tip fields characterized by a triaxiality parameter - II. Fracture Applications. - J. Mech. Phys. Solids, vol.40, No.5, pp.939-963.

[15] Yang S., Chao Y.J. and Sutton M.A. (1993): Higher order asymptotic crack tip fields in a power-law hardening material. - Engineering Fracture Mechanics, vol.19, No.1, pp.1-20.

[16] Hutchinson J.W. (1968): Singular behaviour at the end of a tensile crack in a hardening material. - Journal of the Mechanics and Physics of Solids, vol.16, No.1, pp.13-31.

[17] Rice J.R. and Rosengren G.F. (1968): Plane strain deformation near a crack tip in a power-law hardening material. - Journal of the Mechanics and Physics of Solids, vol.16, No.1, pp.1-12.

[18] Neimitz A., Graba M. and Gałkiewicz J. (2007): An alternative formulation of the Ritchie-Knott-Rice local fracture criterion. - Engineering Fracture Mechanics, vol.74, pp.1308-1322.

[19] Ritchie R.O., Knott J.F., Rice J.R. (1973): On the relationship between critical tensile stress and fracture toughness in mild steel. - Journal of the Mechanics and Physics of Solids, vol.21, pp.395-410.

[20] Graba M. and Gałkiewicz J. (2007): Influence of the crack tip model on results of the finite element method. Journal of Theoretical and Applied Mechanics, Warsaw, vol.45, No.2, pp.225-237.

[21] Graba M. (2011): The influence of material properties and crack length on the Q-stress value near the crack tip for elastic-plastic materials for single edge notch plate in tension. - Archives of Civil and Mechanical Engineering, vol.11, No.2, pp.301-319.

[22] Graba M. (2012): The influence of material properties and crack length on the Q-stress value near the crack tip for elastic-plastic materials for centrally cracked plate in tension. - J. Theor. Appl. Mech., vol.50, No.1, pp.23-46.

[23] Graba M. (2008): The influence of material properties on the Q-stress value near the crack tip for elastic-plastic materials. - Journal of Theoretical and Applied Mechanics, vol.46, No.2, pp.269-290.

[24] Graba M. (2012): Catalogue of the numerical solutions for SEN(B) specimen assuming the large strain formulation and plane strain condition. - Archives of Civil and Mechanical Engineering, Published by Elsevier, vol.12, No.1, pp.29-40. 
[25] FITNET Report, (European Fitness-for-service Network), Edited by Kocak M., Webster S., Janosch J.J., Ainsworth R.A. and Koers R., Contract No. G1RT-CT-2001-05071, 2006.

[26] Neimitz A., Dzioba I., Graba M. and Okrajni J. (2008): The assessment of the strength and safety of the operation high temperature components containing crack. - Kielce University of Technology Publishing House, Kielce.

[27] Gałkiewicz J. and Graba M. (2006): Algorithm for determination $\widetilde{\sigma_{i j}}(n, \theta), \widetilde{\varepsilon_{i j}}(n, \theta), d_{n}(n, \theta)$ and $I_{n}(n)$ functions in Hutchinson-Rice-Rosengren solution and its $3 D$ generalization. - Journal of Theoretical and Applied Mechanics, vol.44, No.1 pp.19-30.

[28] Kumar V., German M.D. and Shih C.F. (1981): An engineering approach for elastic-plastic fracture analysis. Electric Power Research Institute, Inc. Palo Alto, CA, EPRI Report NP-1931.

[29] ADINA 8.8, ADINA (2011): User Interface Command Reference Manual-Volume I: ADINA Solids \& Structures Model Definition. - Report ARD 11-2, ADINA R\&D, Inc..

[30] ADINA 8.8, ADINA (2011): Theory and Modeling Guide-Volume I: ADINA Solids \& Structures. - Report ARD 11-8, ADINA R\&D, Inc..

[31] Sumpter J.D.G. and Forbes A.T. (1992): Constraint Based Analysis of Shallow Cracks in Mild Steel. TWI/EWI/IS International Conference on Shallow Crack Fracture Mechanics Test and Application, M.G. Dawes, Ed., Cambridge, UK, paper 7.

[32] Guo W. (1995): Elastoplastic Three Dimensional Crack Border Field - III. Fracture Parameters. - Engineering Fracture Mechanics, vol.51, No.1, pp.51-71.

[33] Chauhan S., Chattopadhyay J. and Dutta B. K. (2016): Limit load equations for miniature single edge notched tensile specimens. - Transactions of the Indian Institute of Metals, vol.69, No.2, pp.641-646.

[34] Graba M. (2013): Numerical verification of the limit load solutions for single edge notch specimen in tension. Archives of Civil and Mechanical Engineering, vol.13, No.1, pp.45-56.

[35] Graba M. (2016): Limit load solutions for SEN(T) specimens - 2D and 3D. - International Journal of Applied Mechanics and Engineering, vol.21, No.3, pp.569-580.

[36] Anderson T.L. (2000): Fracture Mechanics - Fundamentals and Applications. - CRC Press, Corporate Blvd., N.W., Boca Raton, Florida 33431.

[37] Kudari S.K., Maiti B. and Ray K.K. (2007): The effect of specimen geometry on plastic zone size: A study using the $J$ integral. - The Journal of Strain Analysis for Engineering Design, vol.42, No.3, pp.125-136. https://doi.org/10.1243/03093247JSA252.

[38] Rice J.R. (1968): A path independent integral and the approximate analysis of strain concentration by notches and cracks. - Journal of Applied Mechanics, vol.35, pp.379-386.

[39] Seweryn A. (2003): Numerical methods in fracture mechanics. - Biblioteka Mechaniki Stosowanej, IPPT PAN, Warszawa (in Polish).

[40] Graba M. (2012): Selected fracture criteria of elastic-plastic materials. - Mechanical Review, No.12/2017, pp.2431 (in Polish).

[41] Graba M. (2013): Extension of the concept of limit loads for 3D cases for a centrally cracked plate in tension. Journal of Theoretical and Applied Mechanics, vol.51, No.2, pp.349-362.

[42] R6 procedures (1997): Assessment of the integrity of structures containing defects. - Nuclear Electric-R6 Manuals, Nuclear Electric Ltd, Barnett Way, Barnwood, Gloucester GL4 3RS, United Kingdom.

[43] BS 7910:2013+A1:2015, Guide to methods for assessing the acceptability of flaws in metallic structures. Published by BSI Standards Limited 2015, ISBN 978058089564 7,

http://www.google.pl/url?sa=t\&rct=j\&q=\&esrc=s\&source=web\&cd=2\&ved=2ahUKEwig8IWvqeLiAhUGtYsKH b-UD MQFjABegQIBRAC\&url=http $\% 3 \mathrm{~A} \% 2 \mathrm{~F} \% 2 \mathrm{Fgost}-$ snip.su\%2Fdownload\%2Fbs 79102013 a12015 guide to methods for assessing the accept\&usg=AOvVaw0o xHuneHFxxpgpRTGI8jgY 
[44] Zhu X.-K. and Leis B.N. (2006): Bending modified J-Q theory and crack-tip constraint quantification. - Int. J. Fract., vol.141, No.1-2, pp.115-134.

[45] Tkach Y. and Burdekin F.M. (2012): A three-dimensional analysis of fracture mechanics test pieces of different geometries - Part 1 Stress-state ahead of the crack tip. - International Journal of Pressure Vessels and Piping, pp.93-94:42-50.

[46] Tkach Y. and Burdekin F.M. (2012): A three-dimensional analysis of fracture mechanics test pieces of different geometries - Part 2 Constraint and material variations. - International Journal of Pressure Vessels and Piping, pp.93-94:51-60.

[47] Mostafavi M., Smith D.J. and Pavier M.J. (2010): Reduction of measured toughness due to out-of-plane constraint in ductile fracture of aluminium alloy specimens. - Fatigue Fract. Eng. Mater Struct., vol.33, pp.724-739.

[48] Mostafavi M., Smith D.J. and Pavier M.J. (2011): Fracture of aluminium alloy 2024 under biaxial and triaxial loading. - Eng. Fract. Mech., vol.78, pp.1705-1716.

[49] Yang J., Wang G.Z., Xuan F.Z. and Tu S.T. (2013): Unified characterisation of in-plane and out-of-plane constraint based on crack-tip equivalent plastic strain. - Fatigue Fract. Eng. Mater. Struct., vol.36, pp.504-514.

[50] Mu M.Y., Wang G.Z., Xuan F.Z. and Tu S.T. (2017): Fracture assessment based on unified constraint parameter for pressurized pipes with circumferential surface cracks. - Eng. Fract. Mech., vol.175, pp.201-218.

[51] Xu J.Y., Wang G.Z., Xuan F.Z. and Tu S.T. (2018): Unified constraint parameter based on crack-tip opening displacement. - Eng. Fract. Mech., vol.200, pp.175-188.

Received: February 12, 2019

Revised: April 11, 2019 